\title{
Short-term modeling of hybrid geothermal systems for Model Predictive Control
}

\author{
Iago Cupeiro Figueroa ${ }^{\mathrm{a}, \mathrm{b}}$, Damien Picard ${ }^{\mathrm{a}}$, Lieve Helsen ${ }^{\mathrm{a}, \mathrm{b}}$ \\ ${ }^{a}$ University of Leuven (KU Leuven), Department of Mechanical Engineering, \\ Celestijnenlaan 300 - box 2421, 3001 Leuven, Belgium \\ ${ }^{b}$ EnergyVille, Thor Park 8310, 3600 Genk, Belgium
}

\begin{abstract}
Model Predictive Control (MPC) has shown significant energy savings potential in the operation of building energy systems, yet it needs accurate and simple models for optimization. In hybrid geothermal systems the source-side temperatures affect the system efficiency and its operational feasibility. Since the ground dynamics are rather slow, simplifications such as considering a constant coefficient of performance (COP) are made. We evaluate the added value of including a short-term dynamic borefield model to the controller. Simulations are performed in a heating-dominated building equipped with a hybrid geothermal system for two winter weeks. We consider 4 different modeling strategies where the formulation of the $\mathrm{COP}$ and the return fluid temperature from the borefield is varied in complexity. Results show that using a constant COP results in a bang-bang behavior of the heat pump, while with an accurate prediction of the COP the operation is smoother, saving $0.46 \%, 1.86 \%$ and $2.71 \%$ for low, average and high electricity-to-gas price ratios respectively. Including a short-term borefield model avoids shutting down the heat pump due to safety constraints which saves up to $8.12 \%$ more money while the use of the groundsource is quintupled. Despite reducing the optimization iteration number by almost $18 \%$, simulation time is increased.

Keywords: Hybrid geothermal system, Ground Source Heat Pump, Ground
\end{abstract}

\footnotetext{
${ }^{*}$ Corresponding author

Email address: iago.cupeirofigueroa@kuleuven.be (Iago Cupeiro Figueroa)
} 
heat exchanger, Vertical geothermal boreholes, Short-term heat transfer, Model Predictive Control, Control-oriented modeling, Coefficient of performance

\section{Nomenclature}

$\theta \quad$ Borehole adimensional param- $\beta \quad$ Grid factor or borehole adi-

eter

$D \quad$ Borehole buried depth (m) $\quad 25 \quad g$

${ }_{5} H \quad$ Borehole length (m)

$h \quad$ Borehole segment length (m) or coefficient of convection (W $\left.\mathrm{m}^{-2} \mathrm{~K}\right)$

$t_{r} \quad$ Borehole residence time $(\mathrm{s})$

$t_{s} \quad$ Borefield characteristic time (s)

COP Coefficient of performance (-)

15

GEO Contribution of the ground source $(\%)$

$\rho \quad$ Density $\left(\mathrm{kg} \mathrm{m}^{-3}\right)$

$\tau \quad$ Diffusion time (s)

$d \quad$ Distance $(\mathrm{m})$

${ }_{20} \dot{W} \quad$ Electric power $(\mathrm{W})$

$\eta \quad$ Efficiency (-)

$W \quad$ Electric energy $(\mathrm{J})$ mensional parameter (-)

g-Function (-)

$\dot{m} \quad$ Mass flow rate $\left(\mathrm{kg} \mathrm{s}^{-1}\right)$

Modulation signal (-)

Number of units (-)

$N_{b} \quad$ Number of boreholes (-)

$\Delta t \quad$ Resolution time of the radial $\operatorname{grid}(\mathrm{s})$

$r \quad$ Radius, nominal or outer $(\mathrm{m})$

$\Delta r \quad$ Size of the radial mesh $(\mathrm{m})$

c Specific heat capacity $\left(\mathrm{J} \mathrm{kg}^{-1}\right.$ $\mathrm{K}^{-1}$ ) or specific costs (EUR $\mathrm{kWh}^{-1}$ )

$s \quad$ Slack variable $(\mathrm{K})$ or $\left({ }^{\circ} \mathrm{C}\right)$

SCOP Seasonal coefficient of performance (-)

40 $x \quad$ Shanking space $(\mathrm{m})$ or $\mathrm{x}$-axis

$\alpha \quad$ Thermal diffusivity $\left(\mathrm{m} \mathrm{s}^{-2}\right)$

$\dot{Q} \quad$ Thermal power (W) 


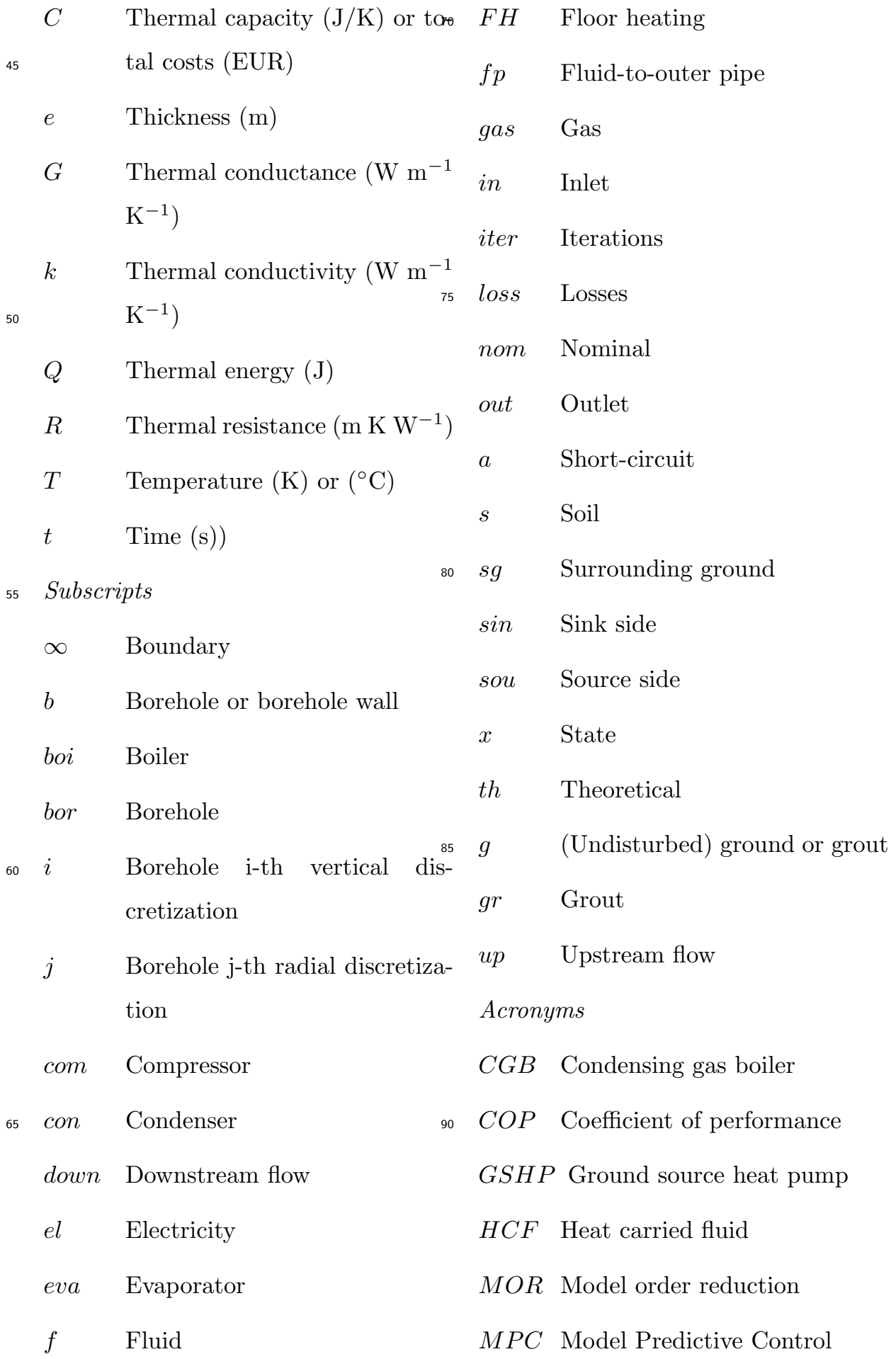


RHC Radiant heating and cooling system

system

TES Thermal energy storage

TABS Thermal activated building

\section{Introduction}

Scientific consensus exists towards increased anthropogenic global warming effects that jeopardize Earth's ecosystems 1]. Initiatives such as the Paris Agreements [2] or European 2030 Targets [3] aim to eliminate these effects, yet unsucessfully; in the year 2018 global energy use increased by $2.3 \%$, driven by a robust global economy and growing demand for heating and cooling needs in buildings. As a result, global energy-related $\mathrm{CO}_{2}$ emissions rose by $1.7 \%$ [4]. The building sector takes a high share, with $36 \%$ of global final energy use and $39 \%$ of energy-related $\mathrm{CO}_{2}$ emissions when upstream power generation is included. Moreover, more than half of this energy is used by space heating, space cooling and water heating [5]. Within this context, geothermal systems are a potential solution towards efficient heating and cooling systems. Ground source heat pumps (GSHPs) can efficiently extract/inject heat from the ground for heating/cooling purposes. Current GSHPs in the market have a coefficient of performance (COP) under nominal conditions $\left(\mathrm{W} 35^{\circ} \mathrm{C}\right.$ outlet of condenser, $\mathrm{B} 0^{\circ} \mathrm{C}$ inlet of evaporator) [6] of 4.5-5. Considering the European primary energy factor (PEF) of 2.1 [7], GSHPs have a primary energy efficiency of 215 to 240\%. Moreover, this COP increases when the difference between the ground and the condenser water is small. Therefore, it is more adequate to couple GSHPs with a radiant heating and cooling ( $\mathrm{RHC}$ ) system [8, 9] as they provide low temperature heating/high temperature cooling and enhanced comfort [10]. Moreover, due to the ground storage capabilities and its range of undisturbed temperatures, passive cooling is possible in summer by means of a simple heat exchanger (HEX). A holistic implementation is the combination of GEOthermal systems with thermally activated building systems (TABS), leading to the GEOTABS concept [11. GEOTABS provides superior performance as the sup- 
ply temperatures for heating/cooling are very low/high, and has thermal energy storage (TES) capabilities due to the large inertia of the building structure and the ground.

However, this kind of system presents several challenges. Firstly, the design of the borefield is a crucial part to ensure the feasibility of the system. In the case of a heating-dominated building, an undersized borefield would compromise the operational feasibility with low heat carrier fluid (HCF) temperatures into the GSHP evaporator, leading to low COPs and even freezing of the HCF. Due to this, it can cause depletion of the ground resource over the years if the building load is unbalanced. An oversized borefield would rapidly escalate the investment costs making the system economically infeasible. Special attention needs to be paid to the ground peak load. In most cases more than $70 \%$ of the borefield length is required to handle the peak load [12. Pure geothermal systems coupled with RHC systems also have the disadvantage that (i) they have to cope fully with the peak loads of the building, (ii) thermal inertia of the system can compromise thermal comfort when there is a sudden change in the heat load and (iii) they lack individual control. A solution is to install a fast-reacting secondary system for heating/cooling that accounts for these peak loads while the GSHP accounts for the base load, leading to hybrid geothermal systems. This secondary system involves an additional supply system (gas boiler, biomass furnace...) and/or an additional fast-reacting emission system (radiators, fan-coil units, ventilation system...). Hybrid geothermal systems introduce additional complexity to the system, making them challenging to control and hampering the envisaged energy savings of the concept if components do not interact in an optimal way, specially considering the differences in prices between two different supply systems (e.g., electricity and gas) and dynamics between two different emission systems (e.g, RHC system and air-based system). Moreover, the geothermal borefield time dynamics are also very slow. Optimal control methodologies that can handle these time delays well, such as model predictive control (MPC), are possible solutions. MPC is a well-known approach in the chemical and automotive industry and has been extensively researched 
over the last decade in the building sector. It uses a model of the system and predictions of the disturbances to forecast its behavior over a prediction horizon and minimizes a cost function under a specific set of constraints. Applied to the building sector, weather and occupancy predictions are used to minimize energy use, operational costs, $\mathrm{CO}_{2}$ emissions, etc... taking into account the different (and variable) energy prices of the supply systems and meeting the required temperature comfort and system constraints [13. MPC has shown savings of 15-30\% in some pilot buildings [14, 15, 16. The combination of the GEOTABS concept with a secondary system and MPC leads to the MPC hybrid GEOTABS concept 17.

One crucial aspect of MPC design is the controller model [18 as it is the most time-consuming and challenging part. The controller models need to be accurate to have reliable predictions but simple enough to be computationally tractable by optimization algorithms. The approaches to obtain controller models go from pure data-driven identification methods (black-box) to physics-based models (white-box), or a combination of both (grey-box). In hybrid geothermal systems, it is important to have a reliable prediction of the GSHP COP. Based on the predicted COP, MPC would optimally distribute the heat loads between the GSHP and the secondary system for the considered prediction horizon. The GSHP COP depends on the operational conditions, mainly on the inlet temperatures of the HCFs into the evaporator and condenser, the mass flow rates through the evaporator and condenser and, in the case of modulating GSHPs, the modulation signal given by the frequency inverter. Moreover, it is important that MPC guarantees the sustainable use of the borefield to avoid operational problems such as freezing in the short-term or depletion of the ground source in the long-term. Hence, reliable GSHP and borefield dynamic controller models for MPC are of vital importance. Since the typical prediction horizons considered in building control range from several hours to a few days, this paper focuses on the short-term dynamics of the geothermal system, parking the long-term sustainable use of the borefield for future work.

A review of borefield modeling for MPC was made by Atam and Helsen [19]. 
Verhelst and Helsen [20] used a 1D ground heat diffusion model of 11 states and applied model order reduction (MOR) and parameter estimation (PE) based on simulation data from the duct-storage (DST) model [21 in TRNSYS for one single borehole. One drawback of the DST model is that it does not take into account the fast borehole dynamics. The proposed model was used by Verhelst 22. The building loads were given making abstraction of the building level, and hourly and weekly time-steps with an horizon of 1 year with perfect predictions were used. For the weekly time-step case, almost no difference was found between a constant formulation of the COP and an equation-fitted one. However, in the case of an hourly time-step, only constant COP was used due to the computational cost of the induced non-linearity, therefore the effects of possible peaks and variable electricity prices between the formulations could not be assessed. Antonov et al. 23] also used the proposed model assuming constant COP due to computational limitations. Atam et al. 24] used proper orthogonal decomposition (POD) to capture the short-term dynamics in a radial diffusion discretised model of the grout and the ground to predict the mean fluid temperature. The borehole piping is approximated by an equivalent diameter model and neglects interactions between boreholes. The extracted model is used in a convexification approach for optimal control where the HP COP is calculated as a linear function of the fluid temperature [25]. The model is also used in different optimization approaches [26, where the HP COP is correlated by a second order polynomial based on TRNSYS data in the non-linear approach and considered constant for the linear approach, with almost no difference between both approaches. In both cases, the building thermal loads were known a priori with a time step of 4 hours. Atam et al. 27] also developed an h-parametrized model for optimization in optimal design frameworks. One drawback of these approaches is that they are estimated based on the output of the TRNSYS Type $557 \mathrm{~b}$ model, which assumes that the boreholes are placed uniformly in a cylindrical storage volume of ground, limiting their applicability to other borefield configurations. De Ridder et al. 28] trained a first order model with data from the DST model to describe the dynamics of the underground storage by using 
the average temperature of the borefield as the unique state, with sampling periods of one week, and considering constant seasonal performance factors for the HP. Atam et al. 29 identified non-linear Hammerstein-Wiener models for different configurations based on large simulation data from BASIMO [30]. Witte et al. [31] developed a physics-based model, however axial heat transfer due to advection is not modeled and the fluid temperature is lumped by using the borehole thermal resistance $R_{b}$. Laferrière and Cimmino 32 used a variable-speed HP model represented by second degree polynomial correlations and a borefield model that requires a discretised thermal response factor as input to compute the ground thermal response in a self-assisted water-to-air GSHP configuration.

Despite all mentioned modelling approaches, most of the reviewed work relies 230 on 'a priori' given building loads, thereby disregarding the difference in dynamic behavior between the RHC system and the secondary system. As mentioned before, those dynamics on the emission-side are necessary since under a sudden peak in the building load the RHC system is not able to respond fast enough and the system needs the less-efficient secondary system to supply part of the load. Only the work by Laferrière and Cimmino [32] considers a building model, but the self-assisted water-to-air GSHP configuration is not equipped with two different emission systems. The question arises whether including a variable non-linear COP which depends on the operation conditions instead of a constant one gives added value when the building emission system dynamics are included in the formulation. And if not, is a borefield control model truly necessary, or could we simplify the problem by considering an infinite source? Is the operation of the borefield jeopardized due to the possibility of freezing the fluid under a peak load? This paper answers these questions and thus also whether these short-term dynamics ought to be included in the formulation and if the GSHP and borefield control models are truly necessary. 


\section{Methodology}

To answer the aforementioned questions, we set up a simulation environment using the system as depicted in Figure 1. A heating-dominated building equipped with a hybrid geothermal system is considered. The borefield is designed to cover most of the energy needs of the building, but not the peak loads, which should be taken over by the secondary system. As a secondary fast-reacting system, a gas boiler injects thermal energy directly into the building's air. A high-fidel model which represents the building in reality is developed using the Modelica IDEAS library [33. Details on the case study design and

the model used for simulation are given in Section 3 . The control inputs of the system are then optimized using TACO 34 optimization environment, which is able to solve non-linear optimization problems (NLPs). TACO requires a control model of the system and some optimization specifications (objective function, set of constraints, prediction horizon...) to compile the optimization problem. State initialization is done using the simulation model. To simplify the optimization problem the fluid mass flow rate on the sink side is considered constant at nominal value. Thus, the control inputs of the system are the modulation signal of the GSHP $y$, the fluid mass flow rate on the source side $\dot{m}_{\text {sou }}$, and the thermal power of the boiler system $\dot{Q}_{b o i}$ which are represented in red in Figure 1. It is important to remark that the model used for simulation and the model used for control are different, causing a model mismatch. This is due to the non-linear solver not being able to handle binary control decision variables such as the temperature protection of the GSHP or the load aggregation algorithm of the ground model, which is based on events.

Due to the model mismatch, the optimized control actions computed by the MPC might not ensure comfort. As the secondary fast-reacting system is, in practice, able to provide comfort at all times, an additional PI controller is included. A number of different MPC strategies, where the GSHP and the borefield system are modelled differently, is evaluated. Therefore, within the optimization environment we are only changing the control model which is in 


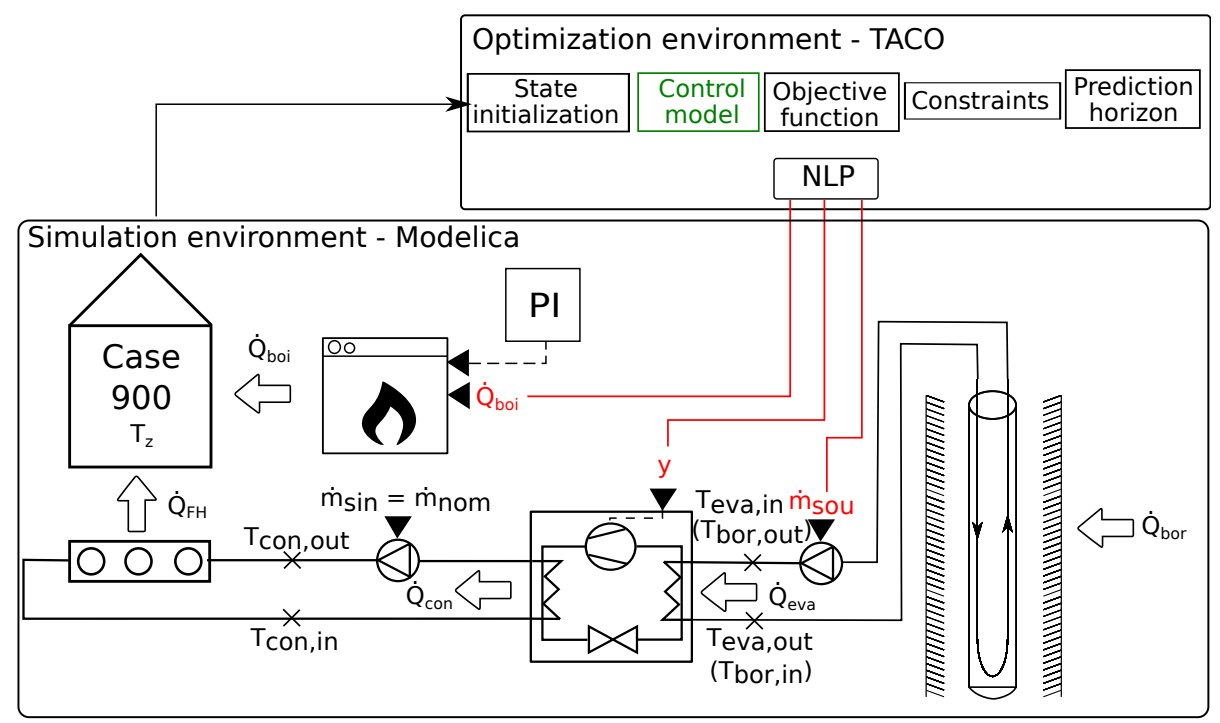

Figure 1: Hybrid geothermal system, nomenclature and main steps used in the research methodology.

green in Figure 1. Section 4 illustrates how the different controller models are formulated. We consider two scenarios to evaluate the different MPC strategies; (i) a scenario with undisturbed ground temperatures representing the start-up phase of the installation to evaluate the economic impact of the different COP formulations, and (ii) a scenario with decreased ground temperature representing the saturated ground after many years of operation to assess the freezing risk possibilities. We expect different behavior of the system in function of the electricity/gas price ratio, therefore for the first scenario different ratios are also evaluated. Section 5 describes the details of the MPC formulation for each considered case while results are discussed in section 6. Finally, conclusions are formulated in Section 7 .

\section{Case study}

The methodology is applied to a slightly modified version of the Case 900 (high inertia) building as described by the BESTEST [35. This section presents the relevant aspects of the building and the way the energy systems (GSHP, 


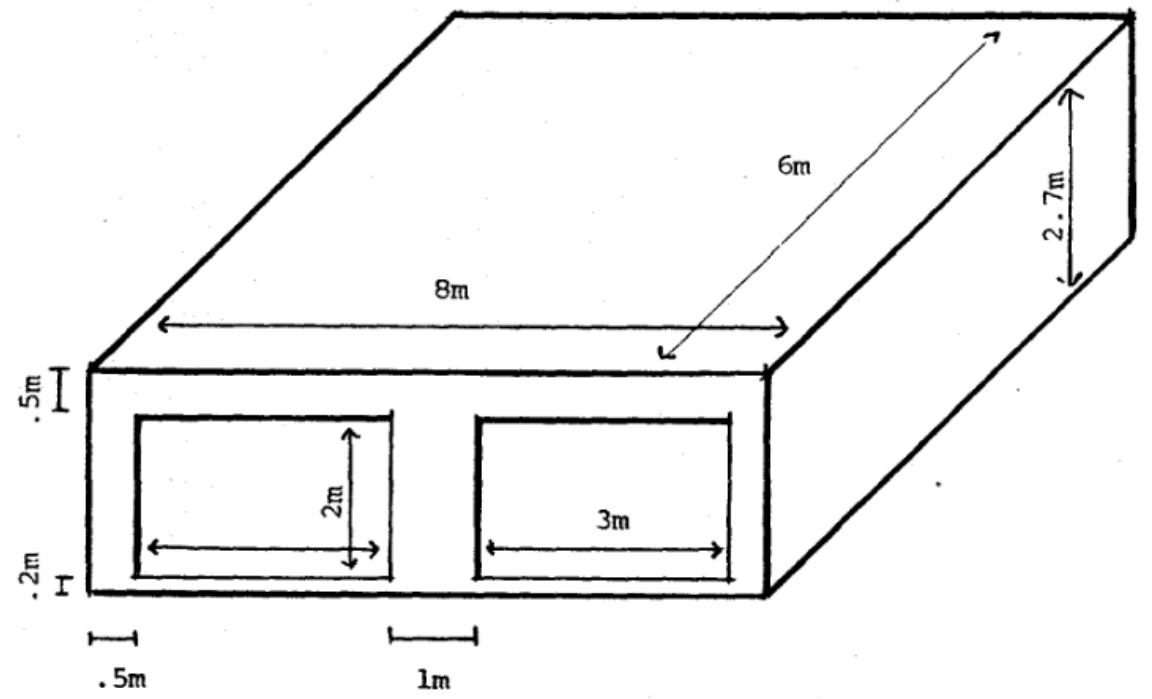

Figure 2: BESTEST structure [35]

borefield and RHC system) are designed. Details on the constructed simulation model to assess the different formulations are also provided.

\subsection{Building envelope}

The Case 900 from BESTEST consists of a $129.3 \mathrm{~m}^{3}$ space with no interior partitions and two south-oriented windows, as depicted in Figure2 2 It represents a relatively heavyweight building with respect to its thermal characteristics. Information about the floor, roofs and outer walls is summarized in Table 1 . The windows have a U-value of $3.0 \mathrm{~W} / \mathrm{m}^{2} . \mathrm{K}$. The air-tightness of the building is given by an $n_{50}$ value of $0.5 \mathrm{ACH}$. No internal heat gains are considered.

The simulation model is constructed using the IDEAS library [33] based on the Modelica language [36]. A verified implementation of the Case 900 is already existing by default within the library. This Case 900 implementation has been slightly modified in the floor component to add the RHC system at $3 \mathrm{~cm}$ beneath the concrete. The RHC component in IDEAS consists of a dynamic embedded pipe model that is connected to the floor component at a specific horizontal 
Table 1: Summary of BESTEST building envelope parameters [35. The layers are ordered from inside to outside

\begin{tabular}{|c|c|c|c|c|c|}
\hline Element & $\mathbf{k}[\mathbf{W} / \mathbf{m K}]$ & $\mathbf{e}[\mathbf{m}]$ & $\mathbf{U}\left[\mathbf{W} / \mathbf{m}^{2} \cdot \mathbf{K}\right]$ & $\rho\left[\mathrm{kg} / \mathbf{m}^{3}\right]$ & $\mathrm{Cp}[\mathrm{J} / \mathrm{kg} . \mathbf{K}]$ \\
\hline \multicolumn{6}{|l|}{ Outer wall } \\
\hline Concrete block & 0.51 & 0.1 & 5.1 & 1400 & 1000 \\
\hline Foam insulation & 0.04 & 0.0615 & 0.651 & 10 & 1400 \\
\hline Wood siding & 0.14 & 0.009 & 15.556 & 530 & 900 \\
\hline Total & & & 0.556 & & \\
\hline \multicolumn{6}{|l|}{ Floor } \\
\hline Concrete slab & 1.13 & 0.08 & 14.125 & 1400 & 1000 \\
\hline Insulation & 0.04 & 1.007 & 0.04 & 10 & 10 \\
\hline Total & & & 0.04 & & \\
\hline \multicolumn{6}{|l|}{ Roof } \\
\hline Plasterboard & 0.16 & 0.01 & 16 & 950 & 840 \\
\hline Fibreglas quilt & 0.04 & 0.1118 & 0.358 & 12 & 840 \\
\hline Roofdeck & 0.14 & 0.019 & 7.368 & 430 & 900 \\
\hline Total & & & 0.334 & & \\
\hline
\end{tabular}


location, based on [37. The weather TMY file corresponds to the original one provided by BESTEST which is located in Denver and characterized by extreme outdoor air tempertures (down to $-24.4^{\circ} \mathrm{C}$ in winter).

\subsection{Energy systems}

Once the building envelope simulation model is ready, we design the corresponding hybrid geothermal system. To this end, a simulation is run assumming an ideal heating and cooling system to allow us to extract the hourly building loads. The ideal heating and cooling system injects heat whenever the space operative temperature goes below $21^{\circ} \mathrm{C}$ and extracts heat when it goes above $25^{\circ} \mathrm{C}$. This ideal system is controlled by a PI controller to avoid bang-bang behavior of the injection/extraction rates and to have a more realistic profile, with a maximum value given by the design heat load of the space as described by standard ISO12831 [38, taking into account static transmission, infiltration and reheating losses. The hybrid geothermal system is designed such that the GSHP

320 is able to provide most of the energy, while the secondary system takes over the peak loads. Therefore, the building loads are given a cut-off at $30 \%$ of the yearly peak load and the GSHP is sized to provide this load at 100\% modulation and nominal conditions. The GSHP model is based on its vapour-compression cycle and their parameters are calibrated using manufacturer data 39. The model is scaled to provide the desired thermal load at nominal conditions. The GSHP model includes temperature safety bands both at the evaporator and condenser side. When the evaporator/condenser temperatures hit these constraints, the GSHP is turned off with a $5 \mathrm{~K}$ band hysteresis control logic. The lower temperature bound in this case is set at $0^{\circ} \mathrm{C}$. The building loads are transformed to ground loads, assumming the nominal COP of the GSHP for heating and passive cooling for cooling, i.e. the building loads equal the ground loads when extracting heat from the building. The resulting hourly ground load profile is given as an input to the Earth Energy Designer (EED) [40] software, along with a set of borehole geometrical and soil parameters to calculate the size of the borefield, resulting in a length of $64.5 \mathrm{~m}$ for a single U-tube borehole. The input 
Table 2: Summary of the borefield parameters used in EED

\begin{tabular}{|c|c|c|c|c|c|c|c|}
\hline \multicolumn{4}{|c|}{ Borehole parameters } & \multicolumn{4}{|c|}{ Piping parameters } \\
\hline Notation & Description & Value & Units & Notation & Description & Value & Units \\
\hline$r_{b}$ & Borehole radius & 75.0 & $m m$ & $r_{p}$ & Pipe radius & 20.0 & $m m$ \\
\hline$H_{b}$ & Borehole height & 64.5 & $m$ & $k_{p}$ & Pipe conductivity & 0.5 & $W /(m . K)$ \\
\hline$d_{b}$ & Borehole burial depth & $0.1^{1}$ & $m$ & $e_{p}$ & Pipe thickness & 2.0 & $\mathrm{~mm}$ \\
\hline$n_{b}$ & Borehole number & 1 & - & $x_{C}$ & Pipe spacing & 40.0 & $\mathrm{~mm}$ \\
\hline \multicolumn{4}{|c|}{ Ground parameters } & \multicolumn{4}{|c|}{ Grout parameters } \\
\hline Notation & Description & Value & Units & Notation & Description & Value & Units \\
\hline$k_{s}$ & Ground conductivity & 1.40 & $W /(m . K)$ & $k_{g}$ & Grout conductivity & 1.15 & $W /(m . K)$ \\
\hline$c_{s}$ & Ground heat capacity & 980 & $J /(k g . K)$ & $c_{g}$ & Grout heat capacity & 800 & $J /(k g . K)$ \\
\hline$\rho_{s}$ & Ground density & 1358 & $\mathrm{~kg} / \mathrm{m}^{3}$ & $\rho_{g}$ & Grout density & 1600 & $\mathrm{~kg} / \mathrm{m}^{3}$ \\
\hline
\end{tabular}

parameters chosen in EED are given in Table 2. This information is used to calibrate the borefield model included in IDEAS, based on the implementation done by Laferrière et al. 41. The secondary system is chosen to be a condensing gas boiler (CGB) which is able to provide the yearly peak load of the building, assuming an efficiency of $100 \%$. It is assumed that the CGB is providing the heat directly to the air. The condenser and evaporator hydraulic pumps of the system are sized such that they provide at nominal flow a temperature difference of 5 and $3 \mathrm{~K}$ respectively. The working fluid at the condenser side is water, while in the evaporator side a $25 \%$ propylene glycol mixture is used.

\section{Controller models}

\subsection{Building envelope}

The controller models of the building envelope and the RHC system are extracted following the linearization procedure as described by Picard et al. [42]. Essentially, the radiation and convective heat transfer equations are linearized around a working point. The equations for the solar transmission and absorption through the glazing are highly non-linear and, instead of being linearized,

\footnotetext{
${ }^{1}$ Default value since only one borehole is considered and the model does not account for ambient conditions effects
} 
they are pre-computed and treated as inputs to the extracted state-space model (SSM). The linearization error on the zone temperature is proven to remain below $1{ }^{\circ} \mathrm{C}$.

\subsection{Ground source heat pump}

A common strategy in optimal control of geothermal systems is to assume a constant COP for the GSHP control model, thus simplifying the problem. The condenser heat flux can also be simplified by considering it constant in the case of on/off GSHPs, or linearly dependent on the modulation signal for modulating GSHPs. However, these simplifications usually result in loss of accuracy as in practice the COP and the condenser heat flux will vary to some extent, depending on the operation conditions. Non-linear equation fitting procedures can be used to increase the accuracy of the COP prediction at the expense of increasing the complexity of the MPC problem. We propose the following equation based on the high-fidel simulation model, computing the COP dependency on sink and source temperatures, variable mass flow rates and modulation level:

$$
\begin{aligned}
C O P & =\frac{\dot{Q}_{c o n}}{\dot{W}_{c o m}} \\
\dot{W}_{c o m} & =\frac{\dot{W}_{c o m, t h}}{\eta_{c o m}}+\dot{W}_{\text {loss }} \\
C O P_{t h} & =\frac{\dot{Q}_{c o n}}{\dot{W}_{c o m, t h}}
\end{aligned}
$$

Where $\eta_{\text {com }}$ and $\dot{W}_{\text {loss }}$ are the compressor efficiency and the constant term of the compressor losses, parameters already calibrated from the simulation model. $C O P_{t h}$ and $\dot{W}_{c o m, t h}$ represent the theoretical COP and compressor power of the GSHP. The theoretical COP is calibrated by using the following equation. 


$$
\begin{aligned}
C O P_{\text {th }}=[A & +B\left(T_{\text {con }, \text { in }}-T_{\text {con }, \text { nom }}\right)+C\left(T_{\text {con }, \text { in }}-T_{\text {con }, \text { nom }}\right)^{2} \\
& +D\left(T_{\text {eva }, \text { in }}-T_{\text {eva }, \text { nom }}\right)+E\left(T_{\text {eva }, \text { in }}-T_{\text {eva }, \text { nom }}\right)^{2} \\
& +F\left(\dot{m}_{\text {sin }}-\dot{m}_{\text {sin }, \text { nom }}\right)+G\left(\dot{m}_{\text {sin }}-\dot{m}_{\text {sin }, \text { nom }}\right)^{2} \\
& \left.+H\left(\dot{m}_{\text {sou }}-\dot{m}_{\text {sou }, n o m}\right)+I\left(\dot{m}_{\text {sou }}-\dot{m}_{\text {sou }, n o m}\right)^{2}\right] f(y)
\end{aligned}
$$

Where $f(y)$ is a logarithmic function since a logarithmic dependency was found:

$$
f(y)=J \ln (y)+K
$$

Similarly, we calibrate the condenser heat flux with the same equation structure.

$$
\begin{aligned}
\dot{Q}_{\text {con }}=[L & +M\left(T_{\text {con }, \text { in }}-T_{\text {con }, \text { nom }}\right)+N\left(T_{\text {con }, \text { in }}-T_{\text {con }, \text { nom }}\right)^{2} \\
& +O\left(T_{\text {eva }, \text { in }}-T_{\text {eva }, \text { nom }}\right)+P\left(T_{\text {eva }, \text { in }}-T_{\text {eva }, \text { nom }}\right)^{2} \\
& +Q\left(\dot{m}_{\text {sin }}-\dot{m}_{\text {sin }, \text { nom }}\right)+R\left(\dot{m}_{\text {sin }}-\dot{m}_{\text {sin }, n o m}\right)^{2} \\
& \left.+S\left(\dot{m}_{\text {sou }}-\dot{m}_{\text {sou }, \text { nom }}\right)+T\left(\dot{m}_{\text {sou }}-\dot{m}_{\text {sou }, n o m}\right)^{2}\right] g(y)
\end{aligned}
$$

In this case, $g(y)$ is a power function:

$$
g(y)=U y^{V}
$$

The validation results for the proposed equation are shown in Figure 3 for a typical range of operation conditions. The error typically stays below $5 \%$ when compared to the used simulation model described by [39, except when the condenser temperature and mass flow rate are respectively high or low. However, in the considered case the model rarely reaches supply temperatures to the floor heating higher than $30^{\circ} \mathrm{C}$ and the sink mass flow rate is constant at its nominal value. 

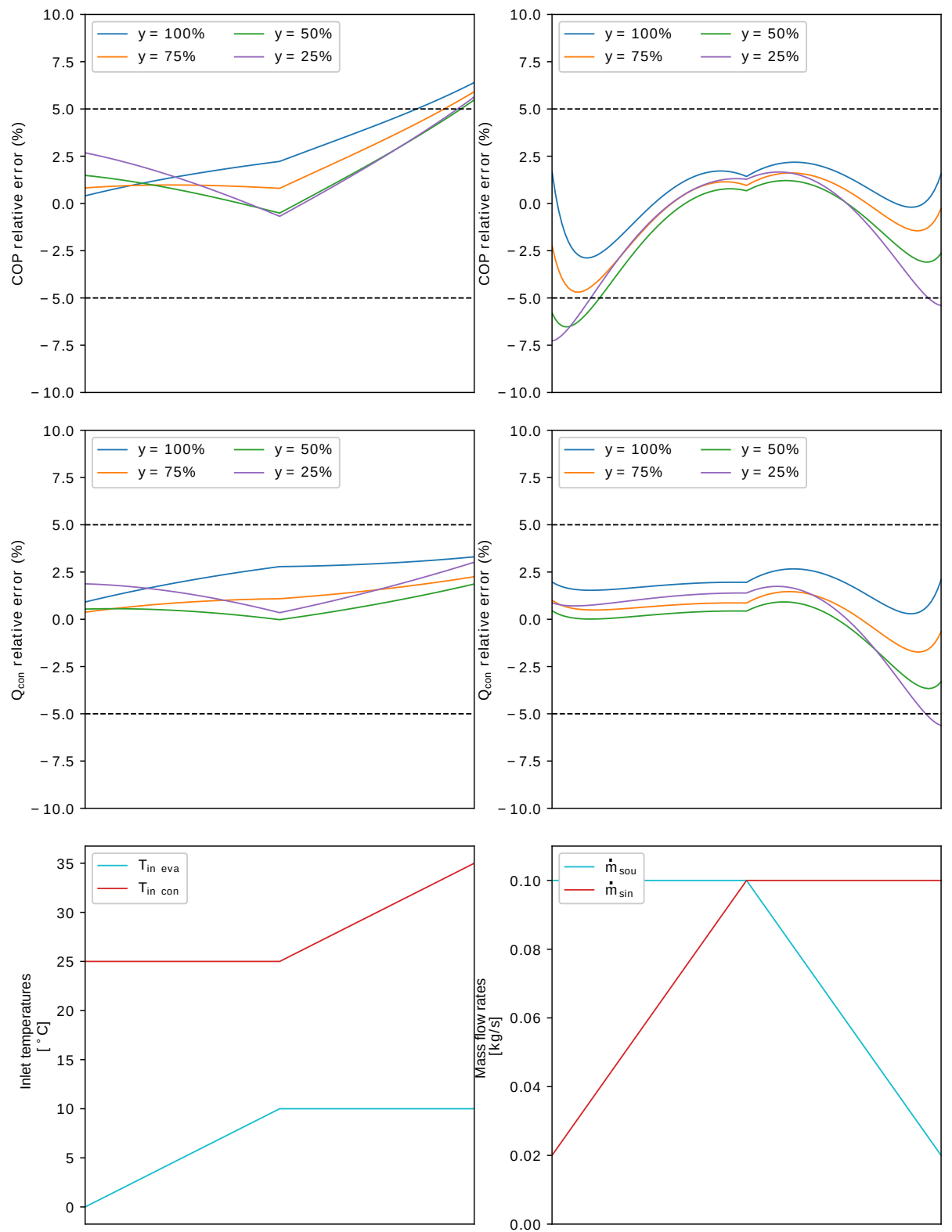

Figure 3: Validation of the GSHP controller model for different modulation levels. Left: Relative error dependency with temperature variation while mass flow rates are kept at nominal conditions (see bottom plot - left for this temperature variation). Right: Relative error dependency with mass flow variation while inlet temperatures are kept at nominal conditions (bottom plot - right for this mass flow variation). 


\subsection{Borefield}

Modeling of borefields has always been challenging due to the different timescales that dominate the heat transfer process. In building control the prediction horizons are in the range of several days. Therefore, for such a timeframe one can assume that the ground temperature, or even the return fluid temperature from the borefield stays stable for the considered prediction horizon. However, these simplifications can reduce the optimality of the solution over the prediction horizon. A sudden ground load will have an influence on the return fluid temperature and the surrounding ground of the borehole, affecting the COP of the GSHP and its operation due to its temperature protection safety bounds. A common strategy in borefield modeling is to split the heat transfer process into two models; the heat transfer within the borehole and the heat transfer outside of the borehole, with the borefield wall temperature acting as a connector between the two models. The proposed model is based on the model developed by Picard and Helsen 43 , and refined by Laferrière et al. 41] for building energy simulations (BES). Its ground response model is based on the characteristic borefield thermal response function with corrections to adapt it to the short-term range and an improved load-aggregation algorithm. However, the implementation of this ground model is unfeasible for continuous non-linear solvers due to the load shifting algorithm. As stated, the timescales of the prediction horizon are in the order of days, therefore we propose small modifications assuming that in such a timeframe long-term effects like thermal interactions between boreholes are not occurring. Due to the MPC receding horizon technique these effects will eventually appear, however to cope with them state update techniques can be applied [44]. Figure 4 shows a schematic representation of the proposed model.

The radial heat transfer happening inside the borehole can be modeled using resistance-capacitance (RC) networks, from the simple Delta-circuit network of Eskilson and Claesson [45, to more accurate networks such as the one developed by Bauer et al. [46. We prefer the latter since Delta-circuits are aimed towards steady-state conditions, only achieved after variations on a time-scale

longer than the borehole characteristic time $t_{b}=\frac{5 r_{b}^{2}}{\alpha_{s}}$. Control time-steps in 


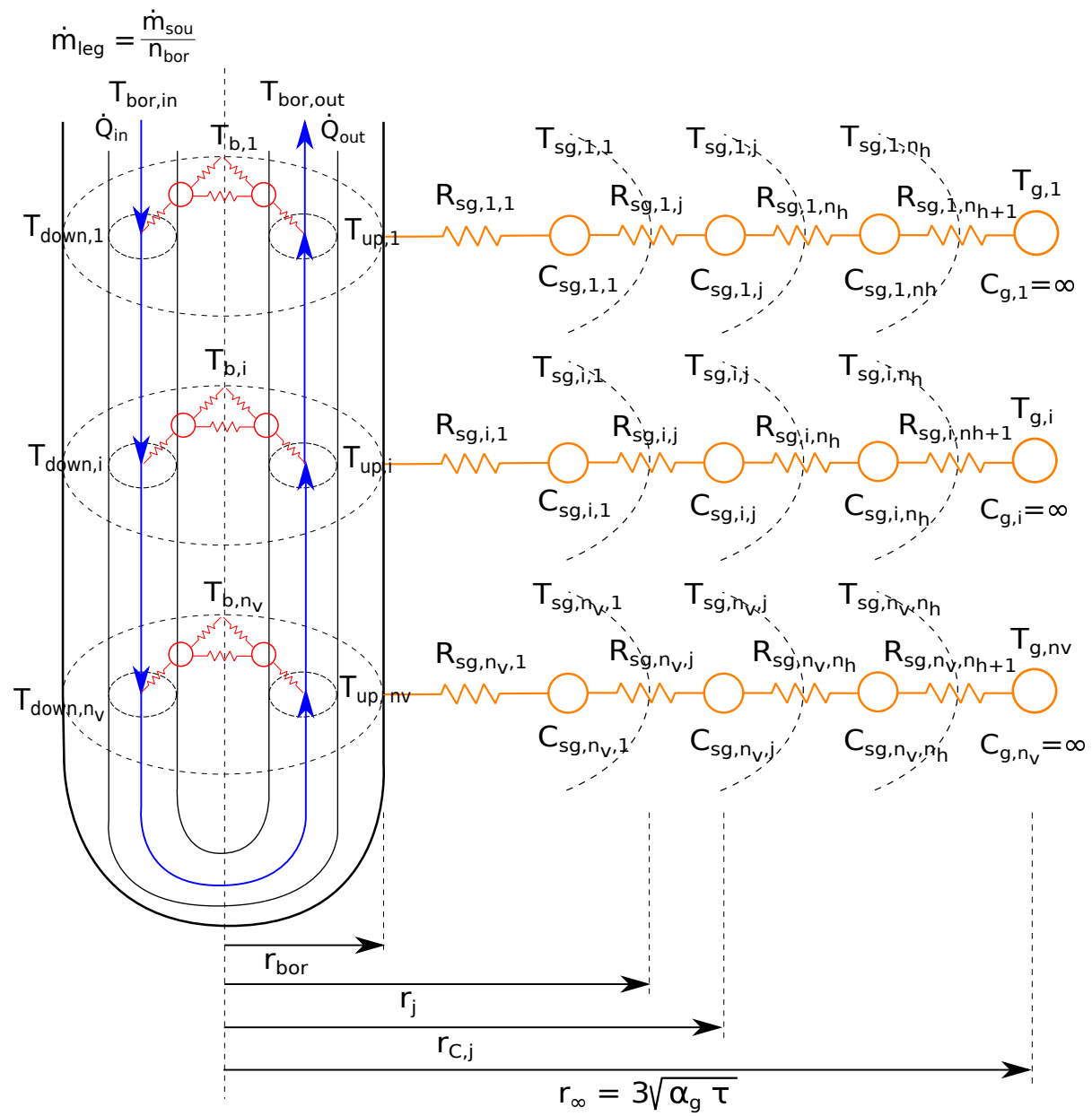

Figure 4: Structure of the proposed borehole model. In red, indicates the radial heat transfer towards the borehole wall. In blue, denotes the axial heat transfer due to advection. In orange, represents the ground radial heat transfer. 
MPC are typically shorter than $t_{b}$, which ranges between 3 and 6 hours 47] and even to more than one day in heavily saturated soils, hence compromising its accuracy within the control interval. The parameters of these networks can be calculated using the so-called 'Multipole method' [4] based on the physical properties of the fluid, piping and grout. To cope with the effects of the fluid circulating through the borehole piping, the borehole radial heat transfer model is discretised vertically $n_{v}$ times and the fluid volumes are coupled with advection heat transfer equations which are for the first discretization:

$$
\begin{gathered}
\dot{Q}_{\text {in }}=\dot{m} C_{p}\left(T_{\text {in }}-T_{\text {down }, 1}\right) \\
\dot{Q}_{\text {out }}=\dot{m} C_{p}\left(T_{\text {up }, 1}-T_{\text {out }}\right)
\end{gathered}
$$

for the mid-discretizations $i=2, \ldots, n_{v}$ :

$$
\begin{aligned}
\dot{Q}_{\text {down }, i-1 \rightarrow i} & =\dot{m} C_{p}\left(T_{\text {down }, i-1}-T_{\text {down }, i}\right) \\
\dot{Q}_{u p, i \rightarrow i-1} & =\dot{m} C_{p}\left(T_{u p, i}-T_{u p, i-1}\right)
\end{aligned}
$$

and for the short-circuit discretization at the bottom of the borehole:

$$
\dot{Q}_{\text {down }, n_{v} \rightarrow u p, n_{v}}=\dot{m} C_{p}\left(T_{\text {down }, n_{v}}-T_{u p, n_{v}}\right)
$$

To model the heat diffusion ocurring in the ground surrounding the borehole, we discretize the surrounding ground into a mesh of $n_{h}$ rings by using a radial 1D RC network for each vertical discretization, with $n_{h}$ being the number of (horizontal) radial discretizations. The mesh is discretized from the borehole radius $r_{b}$ to a boundary radius calculated using the diffusion length $r_{\infty}=3 \sqrt{\alpha_{s} \tau}$, with $\alpha_{s}$ being the thermal diffusivity of the soil and $\tau$ the diffusion time, and provides a measure of how far the temperature has propagated by diffusion in time $\tau$ ([49]). The time $\tau$ should be selected based on the prediction horizon chosen in the MPC formulation. The capacities of the mesh represent the temperatures of the surrounding ground $T_{s g}$. To place the capacities, the cell size $\Delta r_{C}$ is calculated using Eskilson's guidelines [50, as shown in Equation 7]. The 
first three cell sizes are constant, while the remaining cells are exponentially increased by the grid factor $\beta$. At the boundary, an infinite capacity is placed at undisturbed ground temperature $T_{g}$.

$\Delta r_{C}=\left[\Delta r_{C, \text { min }}, \Delta r_{C, \min }, \Delta r_{C, \min }, \beta \Delta r_{C, \min }, \beta^{2} \Delta r_{C, \min }, \ldots, \beta^{n_{h}} \Delta r_{C, \min }, r_{\infty}\right]$

$\Delta r_{C, \min }=\min \left(\sqrt{\alpha_{g} \Delta t}, H / 5\right)$

where $\Delta t$ is the resolution time and is the shortest time interval between changes in the loading condition. The resistances are placed between the capacities at:

$$
r_{j}=r_{C, j-1}+\frac{r_{C, j}-r_{C, j-1}}{2}
$$

The RC parameters are calculated from the physical properties of the surrounding ground:

$$
\begin{aligned}
C_{s g, i, j} & =\rho_{s g, i, j} c_{s g, i, j} h_{i} \pi\left(r_{j+1}^{2}-r_{j}^{2}\right) \\
R_{s g, i, j} & =\frac{\ln \left(\frac{r_{C, i, j}}{r_{C, i, j-1}}\right)}{2 \pi k_{s g, i, j} h_{i}}
\end{aligned}
$$

with $k_{s g}, c_{s g}$ and $\rho_{s g}$ being the thermal conductivity, specific heat capacity and density of the surrounding ground respectively, and $h_{i}$ the height of the i-segment.

\subsubsection{Reducing the order of the borehole model}

The proposed borefield controller model can be considered as a double-input ( $\dot{m}_{\text {sou }}$ and $\left.T_{\text {bor, in }}\right)$ single-output $\left(T_{\text {bor,out }}\right)$ model. In terms of control complexity, each vertical discretization introduces two fluid and two grout states in the case of single- $\mathrm{U}$ pipes, and four fluid and four grout states in the case of double- $\mathrm{U}$ pipes. The ground radial mesh introduces an additional number of states $n_{v} n_{h}$. The infinite capacity placed at the boundary radius introduces an additional state at the end of each radial mesh on purpose, so that these states are subject to being updated. The physical representation of these states are the temperatures of the fluid, grout and ground at different points. The model complexity 
Table 3: Summary of the states $x$ of the controller model.

\begin{tabular}{|l|c|c|}
\hline State meaning & Quantity & Symbol \\
\hline Fluid temp. & $2 n_{v}$ (U-tube) & \\
& $4 n_{v}$ (2xU-tube) & $T_{f, i, k} \begin{array}{c}i=1 \ldots n_{v} \\
k=1,2(3,4)\end{array}$ \\
& 0 (steady-state) & \\
\hline Grout temp. & $2 n_{v}$ (U-tube) & \\
& $4 n_{v}$ (2xU-tube) & $T_{g r, i, k} \begin{array}{c}i=1 \ldots n_{v} \\
k=1,2(3,4)\end{array}$ \\
\hline Ground temp. & 0 (steady-state) & \\
\hline Boundary temp. & $n_{h} n_{v}$ & $T_{s g, i, j} \begin{array}{c}i=1 \ldots n_{v} \\
j=1 \ldots n_{h}\end{array}$ \\
\hline
\end{tabular}

can be varied either by adjusting the number of vertical and/or horizontal discretizations, or by eliminating the dynamics in the fluid/grout by considering steady-state conditions inside the borehole. A summary of the states of the model can be found in Table 3 .

The accuracy/complexity ratio of the proposed borehole model is dependent on the number of discretizations and dynamics chosen. An optimal compromise between the accuracy of the model and its number of discretizations is assessed based on a complexity analysis. Since the borehole model is based on the model developed by [43, 41], it serves as a baseline for comparison in the complexity analysis. The high-fidel simulation borehole model is also discretized vertically and coupled to a ground response model based on the g-function of the considered borefield and an improved load aggregation scheme. We consider 10 vertical discretizations for the baseline model. The analysis is done by applying a heat input step and evaluating the absolute error of the thermal response of the borefield outlet fluid over the borehole steady-state time $t_{b}=\frac{5 r_{b}{ }^{2}}{\alpha_{s}}$. Although we are fixing the heat step input, in the proposed model it has to be defined by a certain fluid mass flow rate and temperature difference. Therefore, we perform the analysis for different values of the adimensional fluid mass flow rate $\frac{2 \pi k_{g} H n_{b o r}}{\dot{m} c_{p}}$ as defined by Cimmino [51]. The methodology to evaluate the 

energy forces a constant step input to be injected into the borehole. We choose the adimensional fluid mass flow rates to be 1.48 and 7.41 as those values correspond to the nominal and minimum fluid mass flow rate at the source side. The thermal response of the outlet fluid temperature is defined by Equation 10 . 445 For a different heat input step, the error scales proportionally. The intention is to mimic what information the MPC would receive from the model after a discretized control input, as it computes the optimization problem and it needs to satisfy the constraints at the selected control intervals.

$$
T_{\text {bor }, \text { out }}(t)-T_{g}=\frac{\dot{Q}}{2 \pi k_{s} H n_{\text {bor }}} g_{s \rightarrow f_{\text {out }}}(t)
$$

Firstly, the borehole model is evaluated for different numbers of vertical considered case, a control time-step of 1 hour is chosen, which corresponds to a 


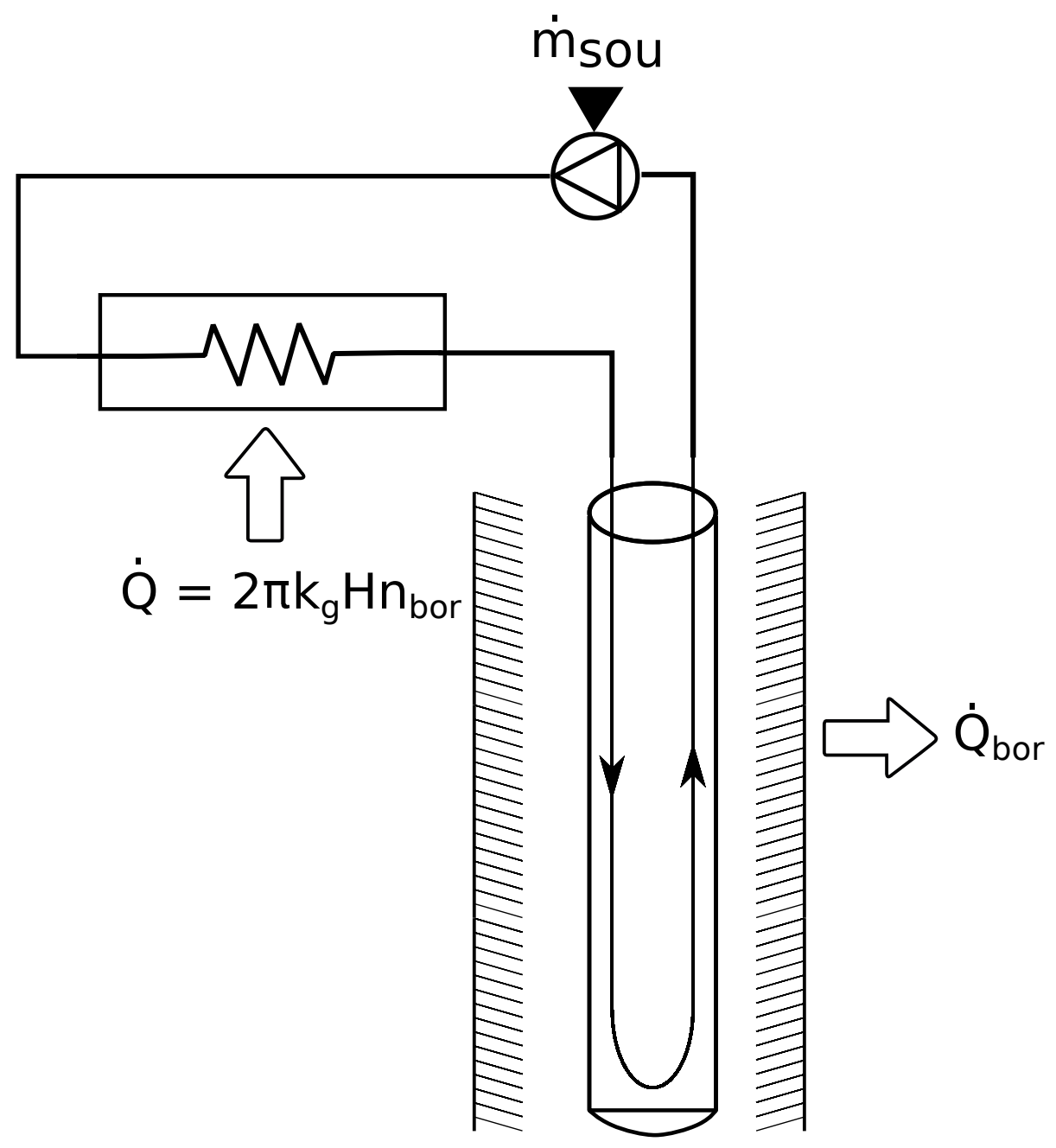

Figure 5: Structure of the model used for the complexity analysis. 

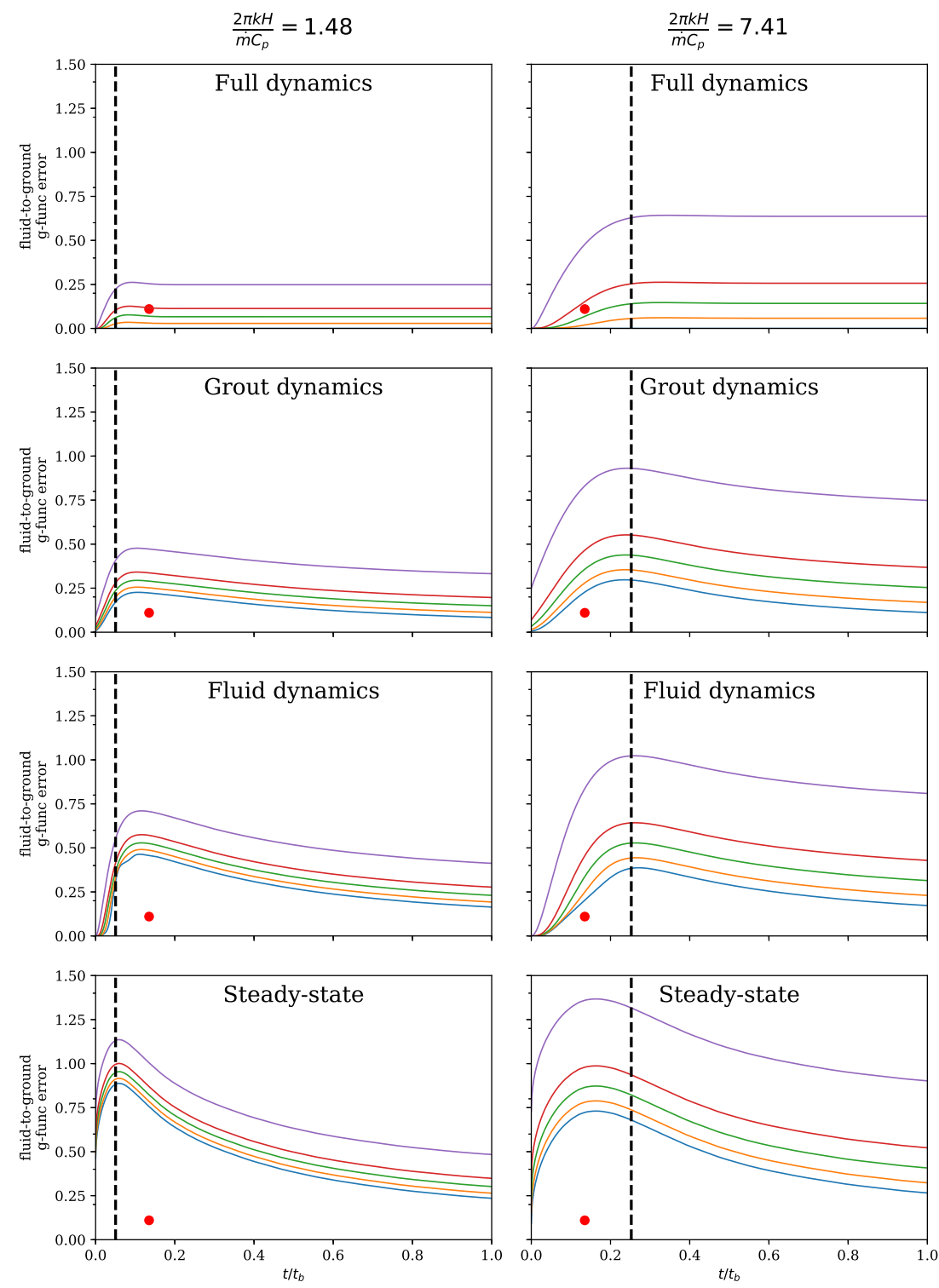

$-n_{v}=10 \quad-n_{v}=5 \quad-n_{v}=3 \quad-n_{v}=2 \quad-n_{v}=1$

Figure 6: Outer fluid-to-ground thermal response error for different numbers of vertical discretizations. The vertical dashed line represents the residence time. Left column: nominal fluid mass flow rate. Right column: $20 \%$ of the nominal fluid mass flow rate. From top to bottom: Both fluid and grout dynamics considered, only grout dynamics considered, only fluid dynamics considered and steady state. 
value of 0.135 in adimensional borehole time terms. We aim to have a maximum prediction error of $0.25^{\circ} \mathrm{C}$. The heat step input is $567.4 \mathrm{~W}$, but the maximum designed ground load is $1282.2 \mathrm{~W}$, meaning that the maximum allowed error of the outlet fluid-to-ground thermal response must be $0.11^{\circ} \mathrm{C}$. The coordinate is represented as a red dot in Figure 6. For this case we conclude that both fluid and grout dynamics need to be taken into account, but the number of discretizations can be reduced down to three. For other cases the adimensional parameters allow positioning the considered case on the graphs of Figure 6 . leading to recommendations with respect to the dynamics to be included as well as the discretization level needed.

Secondly, the discretized ground RC model is compared against the thermal response model used in the baseline to assess its accuracy. According to Eskilson's guidelines a minimum of three $\Delta r_{\min }$ is required, therefore we set the minimum number of states for this model to 4 . Figure 7 shows the fluid-to-

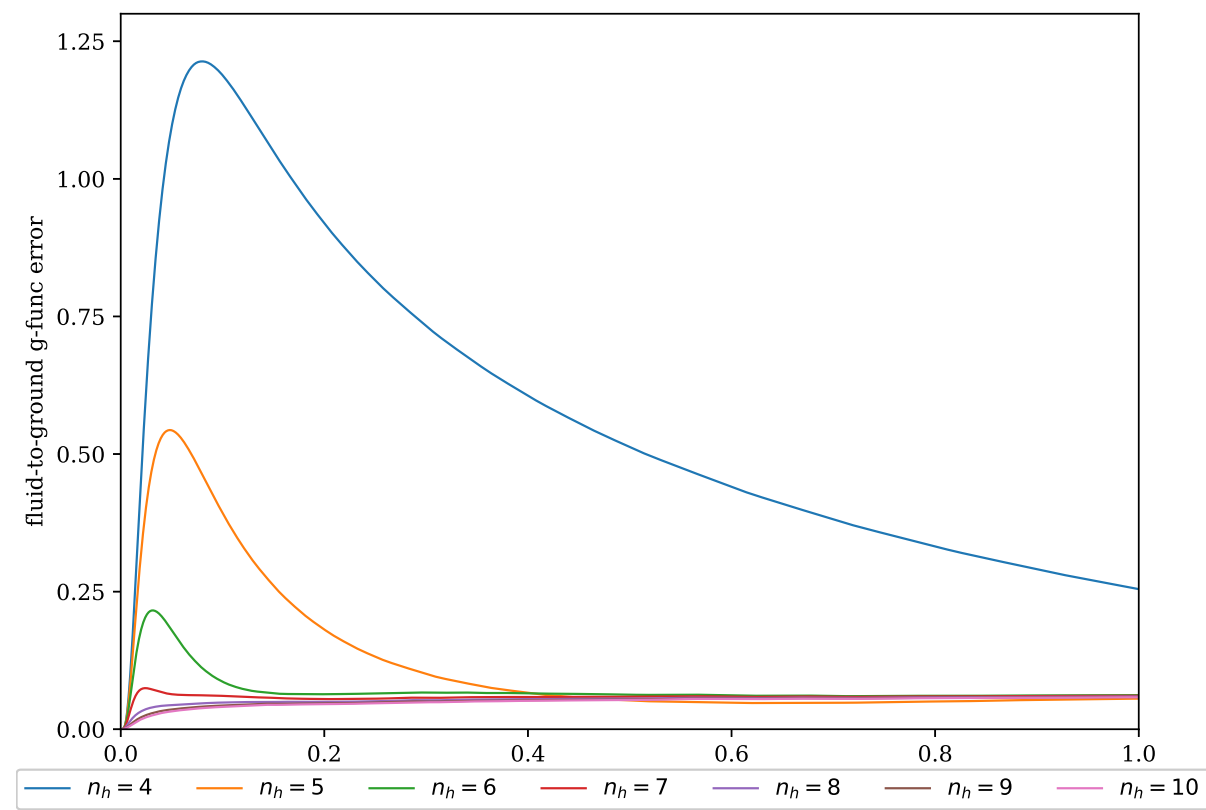

Figure 7: Outer fluid-to-ground thermal response error for different numbers of horizontal discretizations. 
ground thermal response error when compared to the thermal response ground model of the baseline for the considered case. The error is represented adimensionally for the diffusivity time $\tau$ including the whole prediction horizon, as the ground model dynamics are much slower. The effects of different adimensional fluid mass flows are not analysed, and the analysis is carried out at nominal flow value. A steady-state mismatch can be observed between the $\mathrm{RC}$ diffusion network and the baseline thermal response model as the errors are not converging to zero. Following the same considerations as in the borehole case, the number of ground discretizations can be reduced down to 7 . Thus, in total, the baseline model is physically reduced from an initial number of states of 150 to a final number of states of 36 with a minimum loss of accuracy.

\section{MPC formulation}

The MPC controller model is modeled in Modelica and translated using TACO [34]. Based on JModelica [52], TACO translates the Optimica code into an NLP, which is implemented using CasADi [53] and solved using IPOPT. The optimal control results of the NLP are coupled to the simulation model with an external C-code. The formulation of the optimization problem is shown by Equation 11 . 


$$
\min _{y, \dot{Q}_{b o i}, \dot{m}_{\text {sou }}} J=\sum\left(c_{e l} \frac{\dot{Q}_{c o n}}{C O P}+c_{g a s} \dot{Q}_{b o i}+1 e^{4}\left(s_{1}+s_{2}\right)+1 e^{-3} \dot{m}_{\text {sou }}\right) \Delta t
$$

$$
\begin{aligned}
0.2 \leq y & \leq 1.0 \\
0 \leq \dot{Q}_{b o i} & \leq \overline{\dot{Q}_{b o i}} \\
0.2 \bar{m}_{\text {sou }} \leq \dot{m}_{\text {sou }} & \leq \overline{\dot{m}_{\text {sou }}}
\end{aligned}
$$

$$
\begin{aligned}
T_{z} & \geq \underline{T_{z}}-s_{1} \\
T_{\text {eva }, \text { out }} & \left.\geq \underline{\left(T_{\text {eva }, \text { out }}\right.}+0.25\right)-s_{2} \\
s_{1} & \geq 0 \\
s_{2} & \geq 0
\end{aligned}
$$

$$
\begin{aligned}
T_{\text {eva,in }} & \leq T_{\text {con }, \text { in }} \\
T_{\text {eva }, \text { in }}-T_{\text {eva,out }} & \leq 5 \\
T_{\text {con,out }}-T_{\text {con,in }} & \leq 5
\end{aligned}
$$

The objective function is formulated in Equation (11a) and aims at minimizing the operation cost. The first term of the equation represents the power used by the GSHP compressor $\frac{\dot{Q}_{c o n}}{C O P}$ weighted by the electricity $\operatorname{cost} c_{e l}$, while similarly the second term of the equation represents the power used by the CGB weighted by the gas cost $c_{\text {gas }}$. The third term of the equation corresponds to minimization of the slack variables. A large weight adapted by trial-and-error is imposed to give high priority to this term. These slacks represent the thermal discomfort $s_{1}$ and the freezing risk $s_{2}$. Finally, the fourth term of the equation minimizes the mass flow rate at the source side. The controller models used in this case directly prescribe the mass flow to the circuit and therefore it is not possible to compute the electrical power that the hydraulic pumps are using to be included in the objective. Despite that, it is assumed that the hydraulic 
pumps use substantially less energy than the GSHP. Subsequently, this term is weighted with a small constant to give it low priority, and therefore indicates the NLP to minimize it if this does not concur on an extra cost.

The constraints of the NLP are summarized in Equations (11b $11 \mathrm{k})$. The first set of constraints $11 \mathrm{~b}$ 11d refers to the technical limitations of the components being controlled. We assume that the GSHP is not able to operate under the $20 \%$ level of modulation due to torque issues. Similarly, we impose the same constraint to the source side pump since the sink side pump is running at constant fluid mass flow rate. The second set of constraints $11 \mathrm{e} 11 \mathrm{~h}$ includes the slack variables to avoid infeasibilities in the NLP. For instance, due to model mismatch the state update of the zone temperature can cause it to be out of the comfort bounds, causing the infeasibility and non-convergence of the NLP. The same reasoning applies to the evaporator temperature leaving the GSHP, which is constrained to avoid malfunctioning of the GSHP due to the low temperature protection feature. The slacks minimum value is zero and they can therefore be minimized at the objective function to ensure that the inequality is met. The minimum temperature of the building zone $\underline{T_{z}}$ is adapted with a night set-back, being $21^{\circ} \mathrm{C}$ during the day and $16^{\circ} \mathrm{C}$ during the night. The lower temperature protection bound of the GSHP $T_{\text {eva }}$ is set at $0.25^{\circ} \mathrm{C}$ to avoid hitting the bound of $0^{\circ} \mathrm{C}$ in the simulation model. The last set of constraints $(11 \mathrm{i} \mid 11 \mathrm{k})$ is imposed to ensure correct behavior of the GSHP controller model and avoid non-physical temperature differences.

The MPC strategy solves the NLP each hour, with a prediction horizon of 7 days. To avoid an excessive number of control time-steps that could burden the computational load, an increasing time-step strategy is used, i.e. the timestep can increase at each control interval. In our set-up, we select 13 control intervals structured as depicted in Table 4 . The optimal inputs remain constant between each control time-step. Regarding uncertainties, we consider perfect ${ }_{540}$ state update and perfect weather predictions. 
Table 4: Prediction horizon considered. Minimum time-step of $1 \mathrm{~h}$.

\begin{tabular}{|l|c|c|c|c|c|c|c|c|c|c|c|c|c|}
\hline Interval no. & 1 & 2 & 3 & 4 & 5 & 6 & 7 & 8 & 9 & 10 & 11 & 12 & 13 \\
\hline Interval size & $1 \mathrm{~h}$ & $1 \mathrm{~h}$ & $1 \mathrm{~h}$ & $1 \mathrm{~h}$ & $2 \mathrm{~h}$ & $2 \mathrm{~h}$ & $4 \mathrm{~h}$ & $4 \mathrm{~h}$ & $8 \mathrm{~h}$ & $24 \mathrm{~h}$ & $24 \mathrm{~h}$ & $48 \mathrm{~h}$ & $48 \mathrm{~h}$ \\
\hline Time elapsed & $1 \mathrm{~h}$ & $2 \mathrm{~h}$ & $3 \mathrm{~h}$ & $4 \mathrm{~h}$ & $6 \mathrm{~h}$ & $8 \mathrm{~h}$ & $12 \mathrm{~h}$ & $16 \mathrm{~h}$ & $1 \mathrm{~d}$ & $2 \mathrm{~d}$ & $3 \mathrm{~d}$ & $5 \mathrm{~d}$ & $7 \mathrm{~d}$ \\
\hline
\end{tabular}

\subsection{Considered cases}

As we are focusing on the short-term performance of the system, the simulation is run for a winter period of 2 weeks for a number of different scenarios and MPC modeling strategies, which are denoted as cases. Table 5 summarizes the considered MPC modeling strategies ranging in complexity, given by the number of states $n_{x}$. The number of states of the considered building model is 38. The first case is the simplest one and considers a constant $C O P$ and linear dependency of $\dot{Q}_{c o n}$ for the GSHP, and a constant return temperature from the borefield, i.e. the temperature entering into the GSHP evaporator. We increase the complexity of the formulation by updating the return temperature from the borefield at each control time-step via state update using the temperature from the simulation model, therefore adding one additional 'dummy' state. The following step is to increase the complexity of the GSHP model by implementing the non-linear equations for the $C O P$ and the $Q_{c o n}$ formulated in Section 4.2 The correlations of the $C O P$ do not induce any additional state. Finally, in the last case, we include the borefield models depicted in Section 4.3 , addding 150 states for the full order borefield model and 36 after applying the MOR procedure explained in Section 4.3.1. The building model states are initializated at $23^{\circ} \mathrm{C}$, while the borefield states are initializated at ground temperature.

Table 6 summarizes the two considered scenarios. The first scenario represents the installation at the beginning of its life cycle, where the ground temperature has not yet been affected by the geothermal system. This scenario aims to evaluate whether the GSHP operation and the economical impact change substantially. The second scenario represents the status after several years of operation, where the ground temperature has decreased over the years. The 
Table 5: Summary of the considered control modeling strategies.

\begin{tabular}{|c|c|c|c|}
\hline Case \# & GSHP & Borefield & $n_{x}$ \\
\hline 1 & Constant COP \& Linear $\dot{Q}_{c o n}$ & Constant temperature & 38 \\
\hline 2 & Constant COP \& Linear $\dot{Q}_{c o n}$ & Updated temperature & $38+1$ \\
\hline 3 & Non-linear COP \& $\dot{Q}_{c o n}$ & Updated temperature & $38+1$ \\
\hline $4 \mathrm{a}$ & Non-linear COP \& $\dot{Q}_{c o n}$ & Full borefield model & $38+150$ \\
\hline $4 \mathrm{~b}$ & Non-linear COP \& $\dot{Q}_{c o n}$ & Reduced borefield model & $38+36$ \\
\hline
\end{tabular}

Table 6: Summary of the considered scenarios.

\begin{tabular}{|c|c|c|}
\hline Scenario \# & Condition & $T_{g}\left[{ }^{\circ} \mathrm{C}\right]$ \\
\hline I & Undisturbed ground & 10 \\
\hline II & Saturated ground & 5 \\
\hline
\end{tabular}

purpose of this scenario is to evaluate the risk of hitting the safety temperature bounds of the GSHP and the loss of performance when this happens.

Looking at the objective function in Equation 11a, another driver in the optimization is the ratio between the electricity price $c_{e l}$ and the gas price $c_{g a s}$. Different behavior of the GSHP is expected for different ratios between these prices. Based on this ratio and the GSHP COP, the preference of the system towards the gas boiler or the GSHP changes. Since we want to evaluate the different behavior of the GSHP, the different price ratios are considered only for the first scenario. Table 7 shows the considered price ratios, based on European pricing data [54. We consider as baseline case the average EU pricing, the Belgian case as high electricity-gas price ratio and the Swedish case as low electricity-gas price ratio.

\section{Results and discussion}

The simulation is performed on a 6 Core/12 Thread $\operatorname{Intel}(\mathrm{R}) \mathrm{Xeon}(\mathrm{R}) \mathrm{CPU}$ E5-1650 v4 @ 3.60GHz computer. The results are evaluated towards the following key performance indicators (KPIs), some of them defined by Equation 12 
Table 7: Summary of the considered electricity/gas price ratios [54].

\begin{tabular}{|c|c|c|c|}
\hline Reference country & $c_{e l}[c E U R / k W h]$ & $c_{g a s}[c E U R / k W h]$ & Ratio \\
\hline EU average & 20.4 & 6.1 & 3.34 (medium) \\
\hline BE & 28.4 & 5.4 & 5.26 (high) \\
\hline SE & 19.6 & 11.7 & 1.68 (low) \\
\hline
\end{tabular}

total operational costs $c_{t o t}$ for the simulation period (12a), energy contribution of the ground source $G E O$ (12b), and the seasonal coefficient of performance $S C O P$ of the GSHP $12 \mathrm{c}$. Additionally, the computational cost is evaluated for Scenario I in terms of simulation time and the average number of iterations per control step $n_{\text {iter }}$ that the NLP solver needs to converge. The simulation is performed using an Euler integrator with a simulation step of 1s. We found some convergence problems in Case 1 and Case 2, therefore the tolerance of the IPOPT non-linear solver was set to $10 e^{-10}$. The discomfort is not evaluated since it is avoided at all times by the mismatch compensator. The results are also relatively evaluated against the baseline Case 1 .

$$
\begin{aligned}
C_{t o t} & =c_{e l} W_{c o m}+c_{g a s} Q_{b o i} \\
G E O & =\frac{Q_{\text {eva }}}{Q_{c o n}+Q_{b o i}} \\
S C O P & =\frac{Q_{c o n}}{W_{c o m}}
\end{aligned}
$$

\subsection{Scenario I: Undisturbed ground}

Table 8 shows the results for the Scenario I. The simulation results show a clear difference between using a constant $\mathrm{COP}$ and a non-linear COP formulation. Cases 1 and 2 are virtually the same, while the same occurs for Cases 3, 4a and 4b. Figure 8 illustrates the difference between these cases. Cases 1 and 2 present a bang-bang behavior, as the COP is constant and thus independent of the operation conditions. Therefore, when the building needs heat supply the system uses the GSHP as much as possible and the secondary sys- 
Table 8: KPIs of the different considered strategies for scenario I.

\begin{tabular}{|c|c|c|c|c|c|c|}
\hline \multirow{2}{*}{ Strategy \# } & \multicolumn{2}{|c|}{$\mathbf{c}_{\text {tot }}[$ EUR] } & \multicolumn{2}{c|}{ GEO [\%] } & \multicolumn{2}{c|}{ SCOP [-] } \\
\cline { 2 - 7 } & Absolute & Relative (\%) & Absolute & Relative (\%) & Absolute & Relative (\%) \\
\hline 1 & 22.63 & - & 53.89 & - & 5.32 & - \\
\hline 2 & 22.62 & -0.08 & 54.03 & +0.26 & 5.32 & +0.03 \\
\hline 3 & 22.21 & -1.88 & 52.05 & -3.41 & 5.64 & +6.16 \\
\hline $4 \mathrm{a}$ & 22.21 & -1.88 & 52.03 & -3.45 & 5.64 & +6.18 \\
\hline $4 \mathrm{~b}$ & 22.21 & -1.88 & 52.03 & -3.45 & 5.64 & +6.18 \\
\hline
\end{tabular}

tem as a supplementary system. Cases $3,4 \mathrm{a}$ and $4 \mathrm{~b}$ can predict the COP of the GSHP better since their formulation includes the influence of operational parameters. During GSHP peak operation periods, floor heating temperatures are lower and return temperatures from the borefield are higher in Cases 3, 4a and $4 \mathrm{~b}$, leading to a higher COP. The lower modulation input signal also leads to an increase of the SCOP. When a peak is predicted, the GSHP reacts in a smoother way to keep the COP as high as possible and thereby minimizing the costs, and even requiring the CGB to deliver more power when this is more cost-efficient. Eventually this results in a lower ground source contribution for Cases 3, 4 and $4 \mathrm{a}$, but the overall SCOP of the GSHP is $6.17 \%$ higher, and the costs for the two week period are reduced by $1.85 \%$. The COP of the GSHP drives the optimization to some extent and its prediction can vary the results substantially.

The main difference between Case 1 and Case 2 lies in the evaporator fluid mass flow rate, as depicted in Figure 9 . Case 1 is not able to predict that the inlet temperature to the evaporator is being lowered as it assumes it is constant. Therefore, it keeps the fluid mass flow rate at the same value. However, in Case 2 the temperature is being updated at each time-step. Consequently, the fluid mass flow rate adapts to keep the evaporator temperature difference within the range of the constraints. In Cases $3,4 \mathrm{a}$ and $4 \mathrm{~b}$ the fluid mass flow rate remains continuously near the maximum nominal value, as its reduction would negatively affect the COP of the GSHP. A model computing the electrical power 

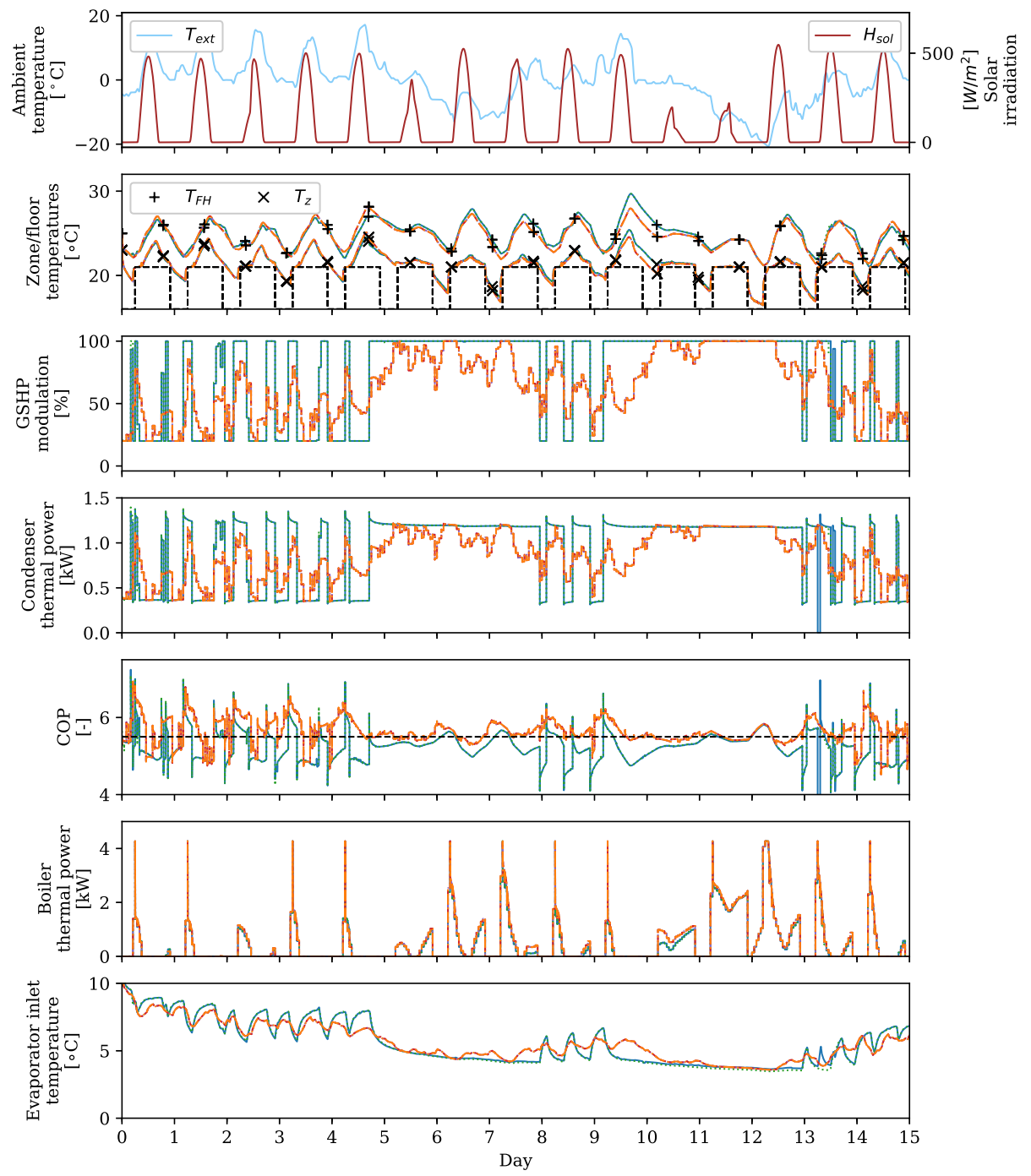

— Case $1 \quad$-........ Case 2 - -...- Case $3 \quad$-.-. Case $4 \mathrm{a} \quad$---- Case $4 \mathrm{~b}$

Figure 8: Operation behavior for scenario I for the different cases. From top to bottom: outdoor temperature and solar irradiation, Zone $(\mathrm{x})$ and floor heating $(+)$ temperatures, GSHP modulation input signal, GSHP condenser thermal power, COP of the GSHP, thermal power delivered by the CGB, evaporator inlet temperature. Results are virtually the same for Cases 1 and 2, and for Cases 3, 4a and 4b. 

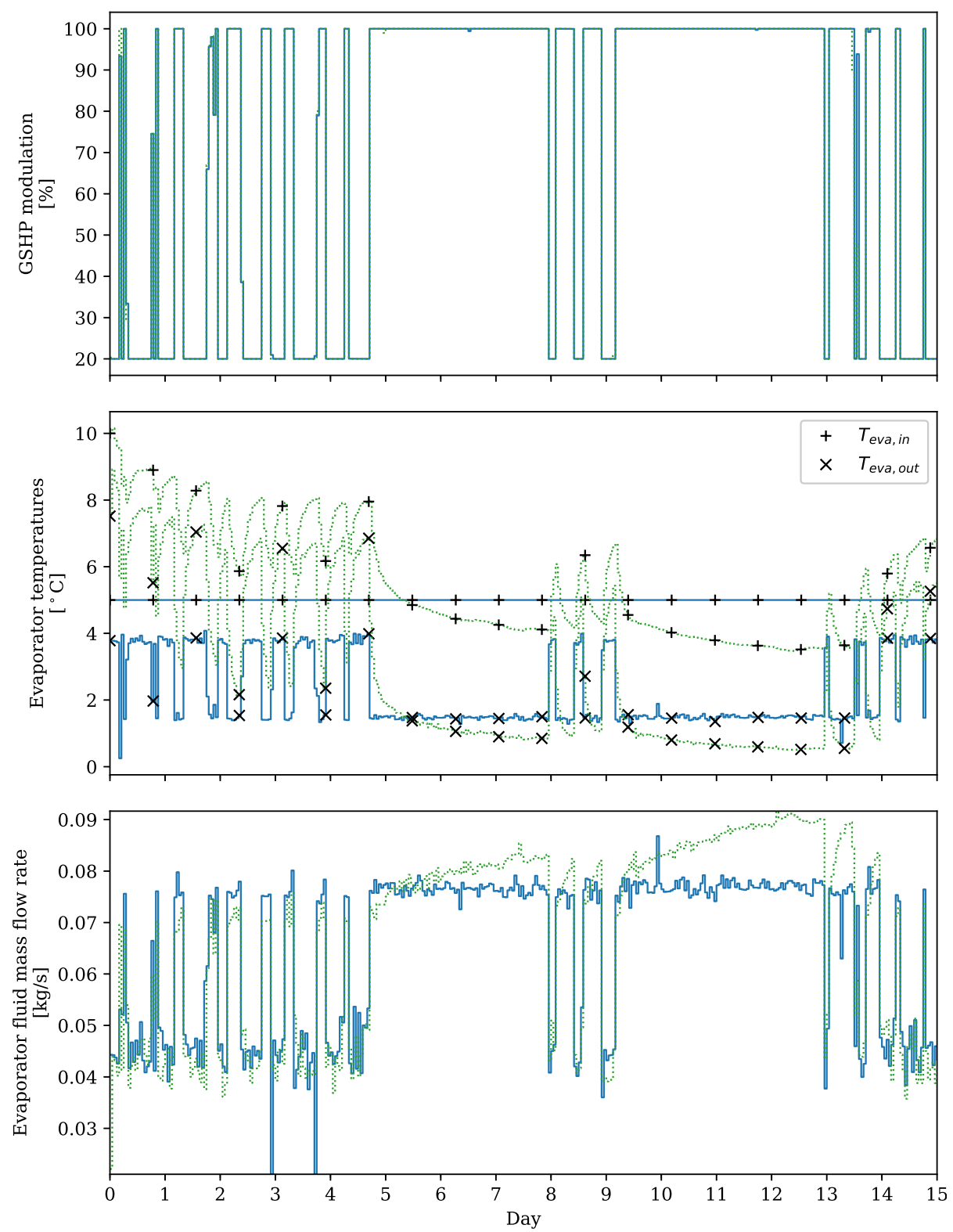

Case $1 \quad \ldots . . . . . \quad$ Case 2

Figure 9: Variation of the evaporator fluid mass flow rate for Cases 1 and 2. From top to bottom: GSHP modulation input signal, MPC 1-step prediction of the inlet $(+)$ and outlet (x) temperatures of the evaporator, Evaporator fluid mass flow rate signal. 
Table 9: Computational cost of the different considered strategies for scenario I.

\begin{tabular}{|c|c|c|c|c|}
\hline \multirow{2}{*}{ Strategy \# } & \multicolumn{2}{|c|}{ Simulation time [s] } & \multicolumn{2}{c|}{$\mathbf{n}_{\text {iter }}[-]$} \\
\cline { 2 - 5 } & Absolute & Relative (\%) & Absolute & Relative (\%) \\
\hline 1 & 415.2 & - & 90.1 & - \\
\hline 2 & 425.3 & +2.43 & 74.1 & -17.76 \\
\hline 3 & 434.3 & +4.61 & 73.9 & -17.98 \\
\hline $4 \mathrm{a}$ & 453.1 & +9.13 & 74.0 & -17.87 \\
\hline $4 \mathrm{~b}$ & 461.6 & +11.17 & 80.7 & -10.43 \\
\hline
\end{tabular}

used by the pump could optimize the trade-off between the increase in COP of the system against the electrical power used by the pump when fluid mass flow rate is increased.

A summary of the computational cost is included in Table 9 In computational terms, it can be seen that by including the non-linear formulation of the COP and the simulation time increases, moreso by including the borefield model. However, we observed that the number of iterations per optimization step is lower in these cases, most likely because the problem is more constrained and this helps the non-linear solver convergence. In the most complex cases there is an increase in simulation time, this presumably because the required time per iteration is longer. Unfortunately, TACO is not able to directly provide either the computational time per iteration or the computational time to reach convergence, therefore it is not possible to provide a more detailed analysis. Suprisingly, the borefield model order reduction augmented the computational time, with practically no influence on the final results. A more comprehensive analysis would be necessary to evaluate the computational cost of each kind of state (fluid, grout and ground).

\subsubsection{Effects of the price ratio}

Looking at the objective function in Equation [11a), another driver of the optimization is the electricity/gas price and efficiencies ratios. For the same 
emission system, it is clear to use the GSHP whenever its COP is higher than the electricity/gas price ratio, weighted with the boiler's efficiency, i.e. $C O P>=\eta_{b o i} \frac{c_{e l}}{c_{g a s}}$. However, the COP where the switch between the GSHP and CGB happens is more challenging to calculate when two emission systems with two very different reacting times are involved, such as the combination of RHC systems and a fast emission system. When using RHC systems, the GSHP condenser heat flow is not injected directly into the building, but stored into the floor/ceiling in the building and released whenever there is a temperature difference between the air and the surface. MPC is strong in keeping the GSHP COP at more cost-effective values. Figure 10 shows the sensitivity of the different inputs of the GSHP and boiler on the electricity/gas price ratio. For the sake of clarity, and since the results are virtually the same for Cases 1 and 2, and Cases 3, 4a and 4b, we only differentiate between a constant COP formulation (Case 2, left) and a non-linear one (Case 4, right). As previously stated, the boiler efficiency is formulated constantly at $100 \%$, i.e. $\eta_{b o i}=1$. The bang-bang behavior persists in all cases where the COP is formulated as a constant value. When the electricity/gas price ratio is sufficiently high, the system shows a higher preference for the gas system which is clearly seen for the Belgian price scenario, where the GSHP is only used as a back-up. It is important to remark that we have established a constant COP value of 5.5, while the price-electricity ratio in this case is 5.26. Despite MPC being given a higher COP than this ratio, the system still has preference for the gas boiler system, highlighting the effect of the building dynamics. However, when the COP is formulated accurately, the system is able to provide a different fraction of geothermal energy. By modulating the GSHP, MPC is able to maximize the GSHP COP and keep it above the threshold value to make it more cost-effective. This behavior is less noticeable when the electricity/gas price ratio is low, such as in the Swedish case. As the electricity price is not much higher than the gas price, the COP threshold value where the GSHP is more cost-effective is lower and far from the current operating region, thus the operation resembles more of a bang-bang behavior. Figure 11 shows the total costs $c_{t o t}$, ground source 
use $G E O$ and the SCOP for the different pricing scenarios and cases. The total cost is reduced in all cases when going from a constant COP formulation to a non-linear one, but the magnitude of these savings is different: while in the case of a low electricity/gas price ratio the difference is almost negligible $(0.46 \%)$, in the case of a high electricity/gas price ratio these savings are more significant $(2.71 \%)$. The contribution of the ground source is increased by $55.34 \%$ in the Belgian scenario, while it is reduced in the scenario with the Swedish and the average-European price ratios by $0.5 \%$ and $3.45 \%$ respectively. This is a consequence of the bang-bang behavior induced by the constant COP formulation: in the Belgian case, most of the time the GSHP is working at its minimum load while the opposite is the case in the Swedish/average-European cases where it is mostly at full load. It can be observed that the difference in the Swedish case is almost negligible since, as we explained before, its operation still resembles the bang-bang behavior. Similarly in regards to the total costs, the SCOP is increased for the three cases when using a non-linear COP formulation, this increase being greater for the case with higher electricity-price ratio. In general, for countries with a high electricity-gas price ratio it is less desirable to use a constant COP formulation since the bang-bang behavior is not able to harness the energy saving potential of the GSHP.

\subsection{Scenario II: Saturated ground}

Table 10 shows the results for Scenario II, which assumes a saturated ground at the start. Including a borefield model results in $8.12 \%$ cost savings. Moreover, 695 Cases $4 \mathrm{a}$ and $4 \mathrm{~b}$ are able to use the ground source 5.2 times more. These increased monetary savings can be achieved since Cases $4 \mathrm{a}$ and $4 \mathrm{~b}$ are able to store the thermal history of the borefield within their states, subsequently being able to optimally use the ground source. The computational cost of the simulation remains in the same trends as in Scenario I.

Figure 12 illustrates the activation of the freezing safety feature, occuring during the first week of simulation. A load peak is predicted ahead, since the outdoor temperature will drop below $-10^{\circ} \mathrm{C}$. Case 1 and Case 2 exhibit bang- 

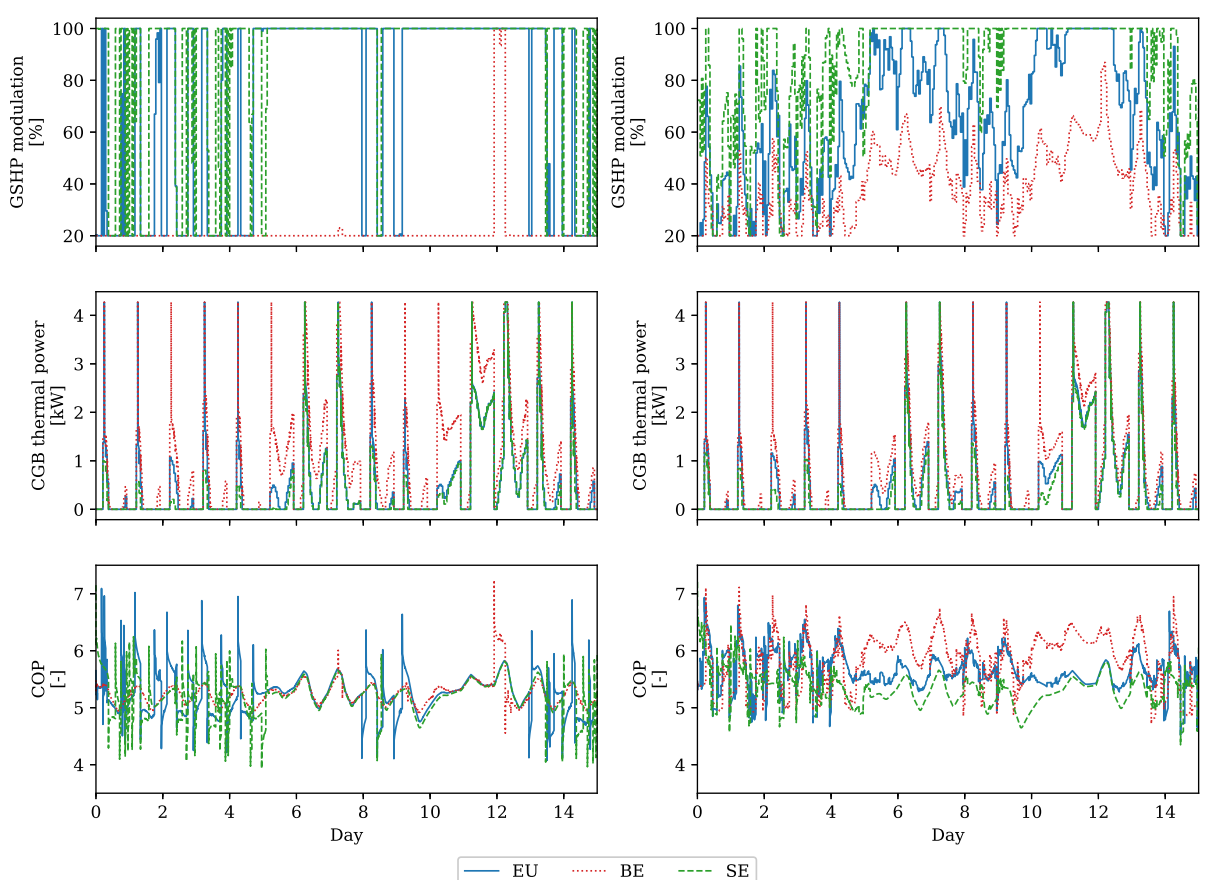

Figure 10: Operation behavior for scenario I for the different price scenarios (EU-BE-SE). Left: COP formulation is constant (Case 2), Right: COP formulation is non-linear (Case 4), From top to bottom: GSHP modulation input signal, thermal power delivered by the CGB, COP of the GSHP
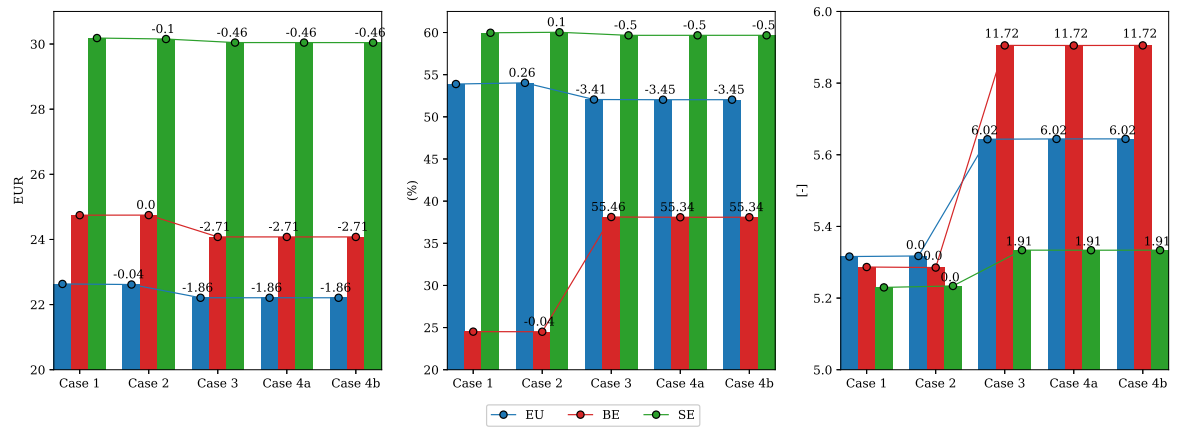

Figure 11: Total cost (left), energy contribution from the ground source (middle) and seasonal COP (right) for the different price ratio scenarios and cases. Relative difference with respect to Case 1 is shown at the top of each bar 

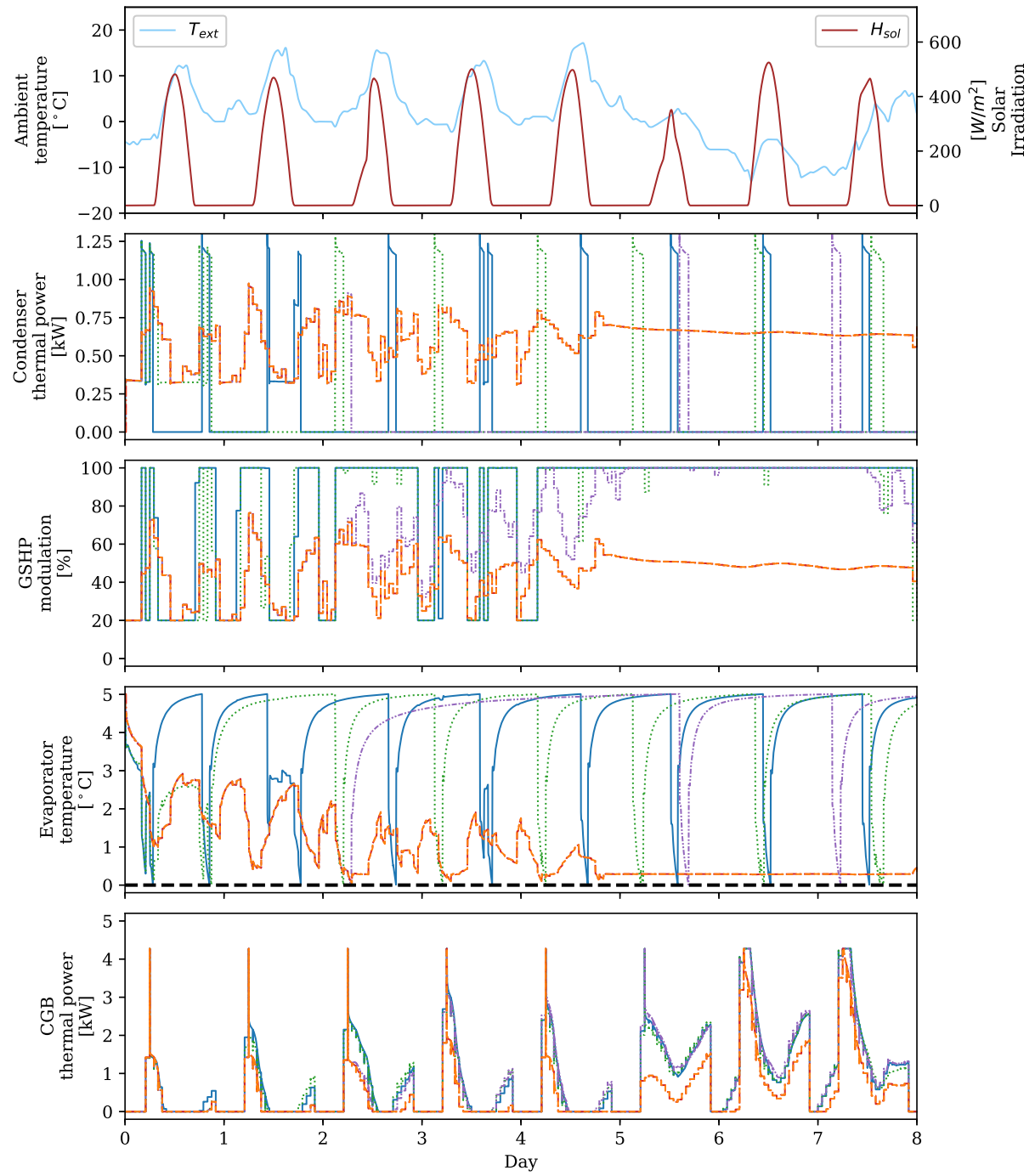

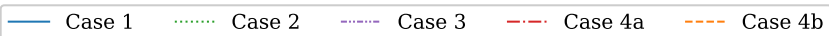

Figure 12: First week of operation for scenario II for the different cases. From top to bottom: outdoor temperature and solar irradiation, condenser thermal power delivered by the GSHP, modulation input signal of the GSHP, temperature in the GSHP evaporator, thermal power delivered by the CGB. 
Table 10: KPIs of the different considered strategies for scenario II.

\begin{tabular}{|c|c|c|c|c|c|c|}
\hline \multirow{2}{*}{ Strategy \# } & \multicolumn{2}{|c|}{$\mathbf{c}_{\text {tot }}[$ EUR] } & \multicolumn{2}{c|}{ GEO [\%] } & \multicolumn{2}{c|}{ SCOP [-] } \\
\cline { 2 - 7 } & Absolute & Relative (\%) & Absolute & Relative (\%) & Absolute & Relative (\%) \\
\hline 1 & 26.08 & - & 7.16 & - & 5.52 & - \\
\hline 2 & 25.89 & -0.72 & 7.49 & +4.61 & 5.65 & +2.34 \\
\hline 3 & 24.67 & -5.41 & 22.94 & +220.39 & 5.47 & -0.90 \\
\hline $4 \mathrm{a}$ & 23.96 & -8.12 & 37.29 & +420.81 & 5.38 & -2.49 \\
\hline $4 \mathrm{~b}$ & 23.96 & -8.12 & 37.29 & +420.81 & 5.38 & -2.49 \\
\hline
\end{tabular}

bang behavior which produces substantial peaks in the ground load. The constant predicted COP generates a mismatch in their computed evaporator heat

maximize the use of the ground source. The evaporator temperature is hitting the imposed constraint. Working constantly under these conditions causes a decrease of the SCOP of the system compared to the other cases. It can be observed also that, after the shut-down, the ground in Case 3 needs more time 

systems. A methodology to construct an accurate borefield controller model based on physical parameters is presented, while the GSHP controller model is based on different equation-fitting procedures. The reduction of the borehole model complexity is analyzed. Since typical prediction horizons of MPC in dynamics of the borehole are modeled. The thermal response of the ground is approximated by an $\mathrm{RC}$ network representing the short-term heat diffusion. The long-term effects are continuously updated via state estimation. The different 
modeling strategies are applied and compared on the BESTEST Case 900, for though these effects are recursively updated via state estimation, they are not included in the optimization per se since it disregards whatever happens after the prediction horizon. The actions taken by the short-term optimization can 

tion of the ground source potential, compromising the economical savings. On the other hand, we have observed how for different pricing scenarios the use of the borefield by MPC differs, but we kept our design rule fixed. In the low electricity-gas price ratio scenario, the size of the borefield could be increased since MPC was overusing the GSHP, which could cause its depletion in the long-term. The design needs to be adapted to the control strategy, which is particularly important in the case of geothermal systems due to the high investment cost of drilling the borefield. Future work will include a formulation of the MPC problem taking into account these long-term effects and design strategies for geothermal systems that cope with the predictive features of MPC.

\section{Acknowledgements}

The authors would like to acknowledge the funding of their research work by the EU within the H2020-EE-2016-RIA-IA programme for the project 'Model Predictive Control and Innovative System Integration of GEOTABS;-) in Hybrid Low Grade Thermal Energy Systems - Hybrid MPC GEOTABS' [grant number 723649 - MPC-; GT].

\section{Appendix A. Adimensional analysis}

The proposed borehole model uses a dynamic RC network to calculate the radial heat transfer that is based on the work of Bauer et al. 46. At the same 805 time, this work relies on steady-state borehole resistances that we calculate using the multi-pole method [48. The multi-pole method calculates the borehole delta-circuit resistances based on the following parameters: 


$$
\begin{aligned}
\beta & =2 k_{g} R_{f p} \\
\theta_{1} & =\frac{k_{s}-k_{g}}{k_{s}+k_{g}} \\
\theta_{2} & =\frac{r_{t u b}}{r_{b o r}} \\
\theta_{3} & =\frac{x_{C}}{r_{b o r}}
\end{aligned}
$$

Where $\beta, \theta_{1}, \theta_{2}$ and $\theta_{3}$ are non-dimensional parameters and $R_{f p}$ is the fluidto-outer pipe resistance, which depends on the piping conductivity $k_{p}$ and the fluid coefficient of convection $h_{f}$. Moreover, by introducing the thermal grout dynamics as depicted by Bauer et al. [46], we include a dependancy on the grout capacity $C_{g}=\rho_{g} c_{g}$. In this appendix we show the variation of the outer fluid-to-ground thermal response for the adimensional parameters $\beta \theta_{1}, \theta_{2}$, and $\theta_{3}$, and different values of the grout capacity $C_{g}$.

Similar to Section 4.3.1. we compare the error to the baseline simulation model case with 10 vertical discretizations. To clarify these dependencies, we consider a single vertical discretization. To keep the parameter $\beta$ constant, e.g. in the cases where $\theta_{2}$ is evaluated, the thermal conductivity of the pipe is properly adapted. Results are shown in Figure A.13. Moving vertically along the plot indicates the level of dynamics considered, similar to Figure 6, while moving horizontally a different adimensional parameter is being evaluated. The values of the parameters when not varied are: $\theta_{1}=3 / 7, \theta_{2}=8 / 25, \theta_{3}=1 / 2$, $\beta=0.6$ and a grout capacity of $C_{g}=3.35 e^{6} \mathrm{~J} / \mathrm{K}$. The results show that for high values of $\theta_{1}$, i.e. high ground conductivity values compared to the grout 825 values, the error increases when the grout dynamics are not being considered. Lower ratios of the piping diameter compared to the borehole diameter $\theta_{2}$ cause a slightly larger maximum error when either grout or fluid dynamics are not being considered. The time where the maximum error appears is shifted since by increasing the piping diameter, the residence time $t_{r}$ also increases. The 
830 causes a smaller error when grout dynamics are not being considered, while the error increases when fluid dynamics are not being considered. There seems to be a minimum shanking value where the maximum error due to the absence of grout dynamics does not increase, while above this value the error is drastically

dynamics to be higher than the error when removing the grout dynamics, as seen in Figure6

\section{References}

[1] N. Oreskes, The scientific consensus on climate change, Science 306 (5702) (2004) 1686-1686. doi:10.1126/science.1103618.

[2] J. Rogelj, M. Den Elzen, N. Höhne, T. Fransen, H. Fekete, H. Winkler, R. Schaeffer, F. Sha, K. Riahi, M. Meinshausen, Paris Agreement climate 

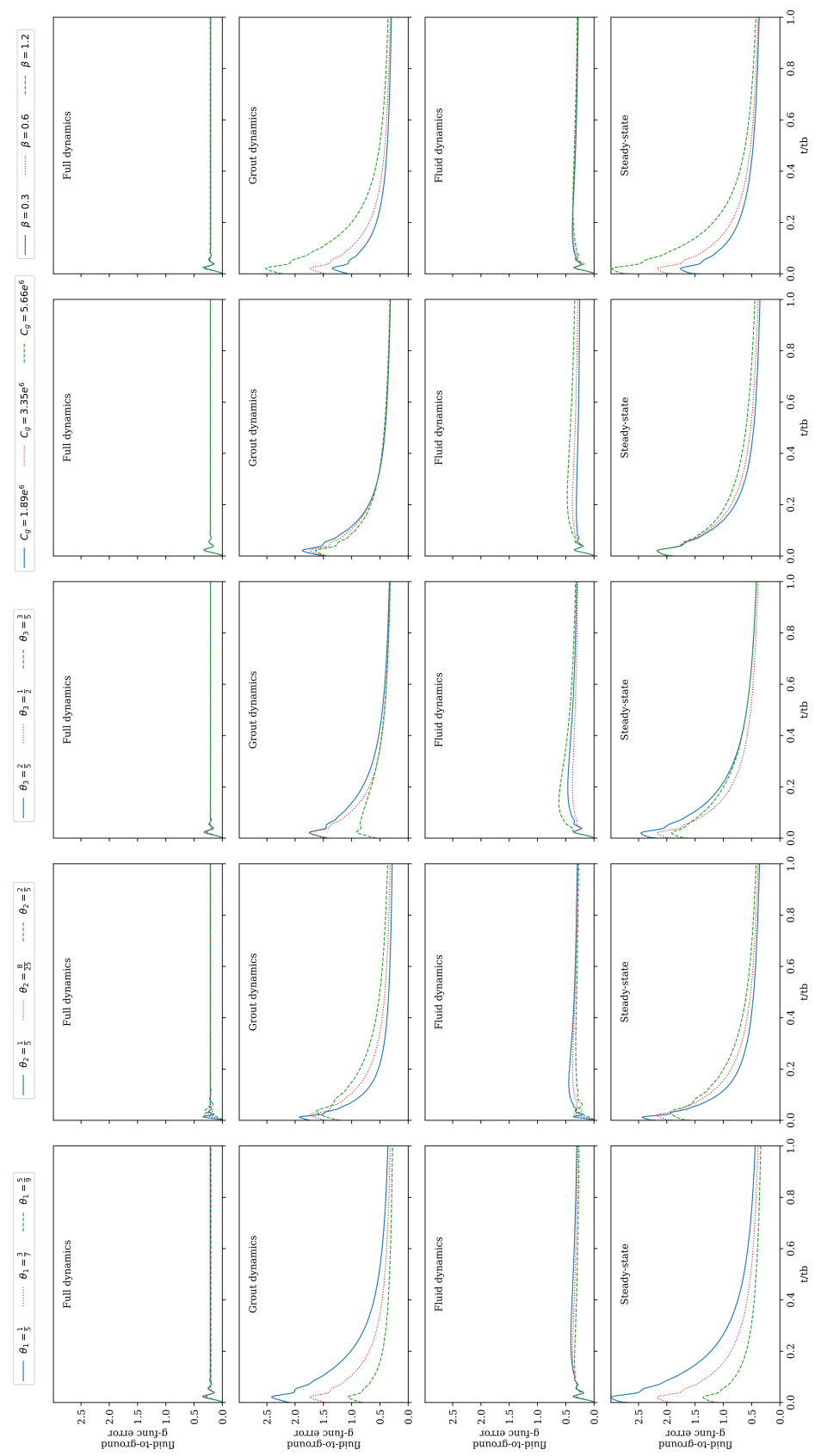

Figure A.13: Outer fluid-to-ground thermal response error for different sets of adimensional parameters. From left to right: variation with $\theta_{1}, \theta_{2}, \theta_{3}$, grout capacity and $\beta$. From top to bottom: Both fluid and grout dynamics considered, only grout dynamics considered, only fluid dynamics considered and steady state. 
proposals need a boost to keep warming well below $2{ }^{\circ} \mathrm{C}$, Nature 534 (7609) (2016) 631. doi:10.1038/nature18307.

860

[3] 2030 Climate \& Energy Framework, https://ec.europa.eu/clima/ policies/strategies/2030_en, accessed: 2019-04-16.

[4] International Energy Agency, Global Energy \& $\mathrm{CO}_{2}$ Status Report (March 2018).

[5] International Energy Agency, Global Status Report - Towards a zer-

[6] EN14511, Air conditioners, liquid chilling packages and heat pumps with electrically driven compressors for space heating and cooling - Part 2: Test conditions, London: BSI.

[7] Council of European Union, DIRECTIVE (EU) 2018/2002 OF THE Directive $2012 / 27 / \mathrm{EU}$ on energy efficiency, https://eur-lex.europa.eu/legal-content/EN/TXT/PDF/?uri= CELEX : 32018L2002\&from=EN (2018).

[8] O. B. Kazanci, M. Shukuya, B. W. Olesen, Exergy performance of different space heating systems: A theoretical study, Building and Environment 99 (2016) 119-129. doi:10.1016/j.buildenv.2016.01.025

[9] O. B. Kazanci, M. Shukuya, B. W. Olesen, Theoretical analysis of the performance of different cooling strategies with the concept of cool exergy, Building and Environment 100 (2016) 102-113. doi:10.1016/j. buildenv.2016.02.013.

[10] K.-N. Rhee, B. W. Olesen, K. W. Kim, Ten questions about radiant heating 【 and cooling systems, Building and Environment 112 (2017) 367-381. doi: $10.1016 / j$. buildenv.2016.11.030 
[11] L. Helsen, Geothermally activated building structures, in: Advances in Ground-Source Heat Pump Systems, Elsevier, 2016, pp. 423-452.

[12] M. A. Bernier, Closed-loop ground-coupled heat pump systems, ASHRAE Journal 48 (2006) 12-25.

[13] I. Cupeiro Figueroa, J. Cigler, L. Helsen, Model Predictive Control formulation: A review with focus on hybrid GEOTABS buildings, Proceedings of the REHVA Annual Meeting Conference, 2018, pp. 1-9.

[14] R. De Coninck, L. Helsen, Practical implementation and evaluation of model predictive control for an office building in Brussels, Energy and Buildings 111 (2016) 290 - 298. doi:10.1016/j.enbuild.2015.11.014.

[15] Z. Vana, J. Cigler, J. Siroky, E. Zacekova, L. Ferkl, Model-based energy efficient control applied to an office building, Journal of Process Control 24 (6) (2014) 790 - 797. doi:10.1016/j.jprocont.2014.01.016

[16] S. R. West, J. K. Ward, J. Wall, Trial results from a model predictive control and optimisation system for commercial building HVAC, Energy and Buildings 72 (2014) 271 - 279. doi:10.1016/j.enbuild.2013.12. 037.

[17] E. Himpe, M. Vercautere, W. Boydens, L. Helsen, J. Laverge, GEOTABS concept and design: state-of-the-art, challenges and solutions, in: REHVA Annual Meeting Conference Low Carbon Technologies in HVAC, 2018.

[18] S. Privara, J. Cigler, Z. Váňa, F. Oldewurtel, C. Sagerschnig, E. Žáčeková, Building modeling as a crucial part for building predictive control, Energy and Buildings 56 (2013) 8-22. doi:10.1016/j.enbuild.2012.10.024.

[19] E. Atam, L. Helsen, Ground-coupled heat pumps: Part 1-literature review and research challenges in modeling and optimal control, Renewable and п Sustainable Energy Reviews 54 (2016) 1653-1667. doi:10.1016/j.rser. 2015.10.007. 
[20] C. Verhelst, L. Helsen, Low-order state space models for borehole heat exchangers, HVAC\&R Research 17 (2011) 928-947. doi:10.1080/10789669. 2011.617188

[21] G. Hellström, Duct ground heat storage model, manual for computer code, Department of Mathematical Physics, University of Lund, Sweden (1989).

[22] C. Verhelst, Model predictive control of ground coupled heat pump systems for office buildings, Katholieke University Leuven, Leuven (2012).

[23] S. Antonov, Should the optimization horizon in optimal control of groundcoupled heat-pump systems cover the interseasonal time scale?, ASHRAE Transactions 120 (2014) 346.

[24] E. Atam, C. Verhelst, L. Helsen, Development of a control-oriented model for borehole dynamics for buildings equipped with ground-coupled heat pumps, in: Proc. 13th Conf. Int. Building Performance Simulation Assoc.(BS 2013), 2013, pp. 2052-2059.

[25] E. Atam, L. Helsen, A convex approach to a class of non-convex building HVAC control problems: Illustration by two case studies, Energy and Buildings 93 (2015) 269-281. doi:10.1016/j.enbuild.2015.02.026.

[26] E. Atam, D. Patteeuw, S. P. Antonov, L. Helsen, Optimal control approaches for analysis of energy use minimization of hybrid ground-coupled heat pump systems, IEEE Transactions on Control Systems Technology 24 (2) (2015) 525-540.

[27] E. Atam, C. Verhelst, L. Helsen, Borehole dynamics parameterization for thermal performance optimization under operational constraints, in: Proc. Euro. Geothermal Congr., 2013, pp. 1-9.

${ }_{935}$ [28] F. De Ridder, M. Diehl, G. Mulder, J. Desmedt, J. V. Bael, An optimal control algorithm for borehole thermal energy storage systems, Energy and 口 Buildings 43 (10) (2011) 2918 - 2925. doi:10.1016/j.enbuild.2011.07. 015 . 
[29] E. Atam, D. O. Schulte, A. Arteconi, I. Sass, L. Helsen, Control-oriented

[30] D. O. Schulte, W. Rühaak, B. Welsch, I. Sass, BASIMO-borehole heat exchanger array simulation and optimization tool, Energy Procedia 97 (2016)

[31] H. J. Witte, A. Cazorla-Marín, J. M. Corberán, An efficient borehole heat exchanger model for the analysis of transient thermal response: comparison with some existing models, in: Proceedings of EnerSTOCK 2018, Adana (Turkey), 25-28 April 2018.

[32] A. Laferrière, M. Cimmino, Model predictive control applied to residential self-assisted ground source heat pumps, in: Proceedings of International Ground Source Heat Pump Association Research Track, 2018, Stockholm (Sweden), 18-20 September 2018.

[33] F. Jorissen, G. Reynders, R. Baetens, D. Picard, D. Saelens, L. Helsen, Implementation and Verification of the IDEAS Building Energy Simulation Library, Journal of Building Performance Simulation 11 (2018) 669-688. doi:10.1080/19401493.2018.1428361.

[34] F. Jorissen, W. Boydens, L. Helsen, TACO, an automated toolchain for model predictive control of building systems: implementation and verification, Journal of Building Performance Simulation 12 (2) (2019) 180-192. doi:10.1080/19401493.2018.1498537.

[35] R. Judkoff, J. Neymark, International Energy Agency building energy simulation test (BESTEST) and diagnostic method, Tech. rep., National Renewable Energy Lab. (1995).

[36] P. Fritzson, V. Engelson, Modelica A unified object-oriented language 
for system modeling and simulation, in: European Conference on ObjectOriented Programming, Springer, 1998, pp. 67-90.

[37] M. Koschenz, B. Lehmann, Thermoaktive Bauteilsysteme tabs, Eidgenössische Materialprüfungs-und Forschungsanst., Zentrum für Energie und , 2000 .

[38] Method for calculation of the design heat load Part 1: Space heating load, Standard, International Organization for Standardization, Geneva, CH (2017).

[39] M. Cimmino, M. Wetter, Modelling of heat pumps with calibrated parameters based on manufacturer data, in: Proceedings of the 12th International Modelica Conference, Prague, Czech Republic, May 15-17, 2017, no. 132, Linköping University Electronic Press, 2017, pp. 219-226.

[40] G. Hellström, B. Sanner, Earth energy designer, Users Manual, version 2 (2000).

[41] A. Laferriere, M. Cimmino, D. Picard, L. Helsen, Development and validation of a full-scale semi-analytical model for the short- and long-term simulation of vertical geothermal borefields, Revised version submitted to Geothermics.

[42] D. Picard, F. Jorissen, L. Helsen, Methodology for obtaining linear state space building energy simulation models, in: Proceedings of the 11th International Modelica Conference, Versailles, France, September 21-23, 2015, no. 118, Linköping University Electronic Press, pp. 51-58.

[43] D. Picard, L. Helsen, A new hybrid model for borefield heat exchangers performance evaluation, in: 2014 ASHRAE Annual Conference, Vol. 120, 2014, pp. 1-8.

[44] I. Cupeiro Figueroa, J. Drgoňa, L. Helsen, State estimators applied to a white-box geothermal borefield controller model, in: 16th IBPSA Conference, Rome (Italy), September 3-5 (2019), IBPSA. 
[45] P. Eskilson, J. Claesson, Simulation model for thermally interacting heat extraction boreholes, Numerical heat transfer 13 (2) (1988) 149-165.

[46] D. Bauer, W. Heidemann, H. Müller-Steinhagen, H.-J. Diersch, Thermal resistance and capacity models for borehole heat exchangers, International Journal of Energy Research 35 (4) (2011) 312-320. doi:10.1002/er.1689

[47] C. Yavuzturk, J. D. Spitler, A short time step response factor model for vertical ground loop heat exchangers, ASHRAE Transactions 105 (2) (1999) 475-485.

[48] J. Claesson, G. Hellström, Multipole method to calculate borehole thermal resistances in a borehole heat exchanger, HVAC\&R Research 17 (6) (2011) 895-911. doi:10.1080/10789669.2011.609927.

[49] R. Bird, W. Stewart, E. Lightfoot, Transport Phenomena., John Wiley and Sons, 1960.

[50] P. Eskilson, Thermal analysis of heat extraction boreholes Ph.D (Doctoral dissertation, Thesis). Department of Mathematical Physics, University of Lund Lund, Sweden (1987).

[51] M. Cimmino, The effects of borehole thermal resistances and fluid flow rate on the g-functions of geothermal bore fields, International Journal of Heat and Mass Transfer 91 (2015) 1119-1127. doi:10.1016/j. ijheatmasstransfer.2015.08.041

[52] J. Åkesson, K.-E. Årzén, M. Gäfvert, T. Bergdahl, H. Tummescheit, Modeling and optimization with Optimica and JModelica.org Languages and tools for solving large-scale dynamic optimization problems, Computers \& Chemical Engineering 34 (11) (2010) 1737-1749. doi:10.1016/j. compchemeng.2009.11.011.

[53] J. Andersson, J. Åkesson, M. Diehl, Casadi: A symbolic package for automatic differentiation and optimal control, in: Recent advances in al- 
a gorithmic differentiation, Springer, 2012, pp. 297-307. doi:10.1007/ 978-3-642-30023-3_27.

[54] ACER, ACER Market Monitoring Report 2017 - Electricity and Gas Retail Markets Volume, Tech. rep., Agency for the Cooperation of Energy Regulators (2018). 